\title{
Novel CCR3 Antagonists Are Effective Mono- and Combination Inhibitors of Choroidal Neovascular Growth and Vascular Permeability
}

Nori Nagai, ${ }^{*}$ Meihua Ju, ${ }^{\star}$ Kanako Izumi-Nagai, ${ }^{*}$ Scott J. Robbie, ${ }^{\dagger}$ James W. Bainbridge, ${ }^{\dagger}$ David C. Gale, ${ }^{\ddagger}$ Esaie Pierre, Achim H.P. Krauss, ${ }^{\top}$ Peter Adamson, ${ }^{*}$ David T. Shima, ${ }^{*}$ and Yin-Shan $\mathrm{Ng}^{*}$

From the Departments of Ocular Biology \& Therapeutics* and Genetics, ${ }^{\dagger}$ University College London Institute of Ophthalmology, London, United Kingdom; the Ophthiris Discovery Performance Unit, ${ }^{\ddagger}$ GlaxoSmithKline, Stevenage Herts, United Kingdom; the Department of Drug Metabolism and Pharmacokinetics ${ }^{\S}$ and the Ophthiris Discovery Performance Unit, ${ }^{\uparrow}$ GlaxoSmithKline, King of Prussia, Pennsylvania

Accepted for publication April 28, 2015.

Address correspondence to Yin-Shan Ng, Ph.D., The Schepens Eye Research Institute, 20 Staniford St., Boston, MA 02114. E-mail: eric_ng@meei.harvard.edu.

\begin{abstract}
Choroidal neovascularization (CNV) is a defining feature of wet age-related macular degeneration. We examined the functional role of CCR3 in the development of CNV in mice and primates. CCR3 was associated with spontaneous CNV lesions in the newly described JR5558 mice, whereas CCR3 ligands localized to CNVassociated macrophages and the retinal pigment epithelium/choroid complex. Intravitreal injection of neutralizing antibodies against vascular endothelial growth factor receptor 2, CCR3, CC chemokine ligand 11/eotaxin-1, and CC chemokine ligand 24/eotaxin-2 all reduced CNV area and lesion number in these mice. Systemic administration of the CCR3 antagonists GW766994X and GW782415X reduced spontaneous CNV in JR5558 mice and laser-induced CNV in mouse and primate models in a dose-dependent fashion. Combination treatment with antivascular endothelial growth factor receptor 2 antibody and GW766994X yielded additive reductions in CNV area and hyperpermeability in mice. Interestingly, topical GW766994X and intravitreal anti-CCR3 antibody yielded strong systemic effects, reducing CNV in the untreated, contralateral eye. Contrarily, ocular administration of GW782415X in primates failed to substantially elevate plasma drug levels or to reduce the development of grade IV CNV lesions. These findings suggest that CCR3 signaling may be an attractive therapeutic target for CNV, utilizing a pathway that is at least partly distinct from that of vascular endothelial growth factor receptor. The findings also demonstrate that systemic exposure to CCR3 antagonists may be crucial for CNV-targeted activity. (Am J Pathol 2015, 185: 2534-2549; http:// dx.doi.org/10.1016/j.ajpath.2015.04.029)
\end{abstract}

Age-related macular degeneration (AMD) is the leading cause of blindness in the developed world. There are two major clinical manifestations of AMD: atrophic (dry) and exudative (wet). Dry AMD is characterized by the degeneration of the retinal pigment epithelium (RPE) and neuroretina, and early stages of the disease are associated with the formation of drusen under the RPE cell layer. Early dry AMD can progress to an end-stage disease in which the RPE degenerates, forming sharply demarcated areas of RPE atrophy or geographic atrophy that leads to secondary death of photoreceptors. When this process affects the macular region of the retina, there is severe vision loss.

Approximately $10 \%$ to $20 \%$ of AMD patients develop choroidal neovascularization (CNV) or wet AMD, which
Supported by an Industrial Collaboration Grant to the University College London Institute of Ophthalmology, Wellcome Trust grant 099173/Z/12/Z, Medical Research Council grant G0800946, National Eye Institute grant EY019943, and GlaxoSmithKline.

N.N. and M.J. contributed equally to this work.

D.T.S. and Y.-S.N. contributed equally as senior authors.

Disclosures: D.T.S. and Y.-S.N. received consulting fees, support, and test compounds for this project and submitted a patent application via GlaxoSmithKline; D.C.G., E.P., A.H.P.K., and P.A. are employees of GlaxoSmithKline. Intravitreal controlled-release devices were provided by pSivida Corp. (Watertown, MA). Y.-S.N. is the guarantor of this work and, as such, had full access to all of the data in the study and takes responsibility for the integrity of the data and the accuracy of the data analysis.

Current address of Y.-S.N., The Schepens Eye Research Institute, Boston, MA. 
accounts for about $80 \%$ of vision loss in AMD. ${ }^{1}$ In both forms of the disease, vision loss occurs due to the death of photoreceptor cells, although in wet AMD, edema and hemorrhage from the hyperpermeable vessels of the CNV cause further and often more acute vision loss. Novel treatments have been developed that address some aspects of wet AMD, in particular the hyperpermeability of the CNV, using molecules that inhibit vascular endothelial growth factor (VEGF). However, patients receiving anti-VEGF therapies require intraocular injections every 6 to 8 weeks to maintain their vision, and the beneficial effects of anti-VEGF therapy typically diminish after the third or fourth year of treatment. ${ }^{2-4}$ Moreover, a significant proportion of $\mathrm{CNV}$ patients do not respond to antiVEGF therapies, ${ }^{5}$ and there are emerging ocular side effects. $^{6-8}$ Alternative and/or adjunct therapies for improving on the existing anti-VEGF therapies are clearly needed.

CCR3 is a $\mathrm{G}$ protein-coupled receptor that, with its ligands, may contribute to the pathogenesis of AMD in general and wet AMD in particular. CCR3 is expressed at significantly higher levels in the tissues of older eyes than in younger eyes, including in the RPE/choroid complex, ${ }^{9}$ and the CCR3 polymorphism rs3091250 is associated with AMD in an Indian population. ${ }^{10} \mathrm{CC}$ chemokine ligand (CCL)-11/eotaxin-1, a natural ligand of CCR3, was identified as a potential serum biomarker of human AMD; in the Age-Related Eye Disease Study, ${ }^{11}$ elevated levels of this chemokine were significantly associated with stage I (early AMD) and stage III (intermediate dry AMD) disease and with geographic atrophy but, interestingly, not with CNV. Examination of postmortem human eyes in this same study suggested a correlation between CCL11 expression and early AMD, intermediate dry AMD, and wet AMD, with the strongest staining observed in the neovascular endothelium of patients with wet AMD. ${ }^{11}$ In another study, however, no difference in circulating CCL11 levels was detected between healthy subjects and AMD patients. ${ }^{12}$ Significantly increased levels of CCL24/eotaxin-2, another natural ligand of CCR3, have been observed in the sera of patients with wet AMD compared with those in normal counterparts, and anti-VEGF treatment in these patients did not reduce the levels of CCL24. ${ }^{13}$

Studies in mouse models have demonstrated therapeutic benefits of CCR3 blockade in treating laser-induced $\mathrm{CNV},{ }^{14,15}$ and photocoagulation studies in mice with a homozygous genetic deficiency for either CCR3 or specific CCR3 ligands demonstrated significant CNV suppression in the mutant mice compared with that in wild-type controls. ${ }^{14}$ Mice deficient in the production of eosinophils or mast cells, the cells most closely associated with the expression of CCR3, were equally sensitive to the induction of CNV by laser injury and to the therapeutic benefits of CNV suppression by CCR3 blockage. ${ }^{14}$ Here we focus on the effects of pharmacological CCR3 blockade in a mouse model of spontaneous $\mathrm{CNV}$, a model that mimics disease progression in humans more closely than does laser-induced CNV, as well as in a primate model of CNV.

\section{Materials and Methods}

\section{Animals}

Eight-week-old female wild-type mice (C57Bl/6) were purchased from Harlan UK Ltd. (Blackthorn, UK), and the JR5558 mice displaying spontaneous CNV were produced from an in-house colony. The animals were fed standard laboratory chow, received water ad libitum, and were housed in a temperature-controlled environment with a 12-hour lightdark cycle. For in vivo procedures, mice were anesthetized with a single i.p. injection of a mixture of medetomidine hydrochloride ( $1 \mathrm{mg} / \mathrm{kg}$ body weight) (Domitor; Pfizer Animal Health, New York, NY) and ketamine $(60 \mathrm{mg} / \mathrm{kg}$ body weight; Fort Dodge Animal Health Ltd., Southampton, UK) in sterile water. When necessary, the pupils were dilated with a drop of $1 \%$ tropicamide (Bausch \& Lomb, Surrey, UK). Before procedures involving laser lesions or fluorescein imaging were performed, pupils were dilated with 1 drop each of $2.5 \%$ phenylephrine hydrochloride (Chauvin Pharmaceuticals Ltd., Kingston-Upon-Thames, UK) and $1 \%$ tropicamide. After the procedures were performed, an i.p. injection of atipamezole 20\% (Antisedan; Orion Pharma, Espoo, Finland) at 0.01 $\mathrm{mL} / 150 \mathrm{~g}$ was used for reversing the effects of the anesthesia.

Male cynomolgus monkeys (Macaca fascicularis) 2 to 4 years of age and weighing 2 to $5 \mathrm{~kg}$ were purchased from Covance Research Products (Denver, PA). Animals were fed Certified Primate Diet no. 2055C (Harlan UK Ltd.), with access to water ad libitum, and maintained at $18^{\circ} \mathrm{C}$ to $26^{\circ} \mathrm{C}$, with a relative humidity of $30 \%$ to $70 \%$, a minimum of 10 air changes per hour, and a 12-hour light-dark cycle. For in vivo procedures, animals were anesthetized using a topical anesthetic $(0.5 \%$ proparacaine; Bausch \& Lomb) instilled in each eye before intravitreal dosing.

All animal procedures were ethically reviewed and approved according to the British Home Office Animals Scientific Procedures Act 1986 and were performed in accordance with European Directive 86/609/EEC; the GlaxoSmithKline Policy on the Care, Welfare and Treatment of Animals; and the Association for Research in Vision and Ophthalmology Statement for the Use of Animals in Ophthalmic and Vision Research.

\section{Small-Molecule Antagonists of CCR3}

GW766994X (free form of GW766994) and GW782415X (hydrochloride salt of GW782415) were synthesized by GlaxoSmithKline (London, UK). Intravitreal controlledrelease devices (polyimide rods) filled with either 0.1 or $0.3 \mathrm{mg}$ GW766994X were purchased from pSivida Corp.

\section{Treatment of Laser-Induced CNV in C57Bl/6 Mice}

Twelve-week-old female C57B1/6 mice were anesthetized i.p. with $25 \mathrm{mg} / \mathrm{kg}$ ketamine hydrochloride and $10 \mathrm{mg} / \mathrm{kg}$ xylazine (Fort Dodge Animal Health Ltd.), and their pupils 

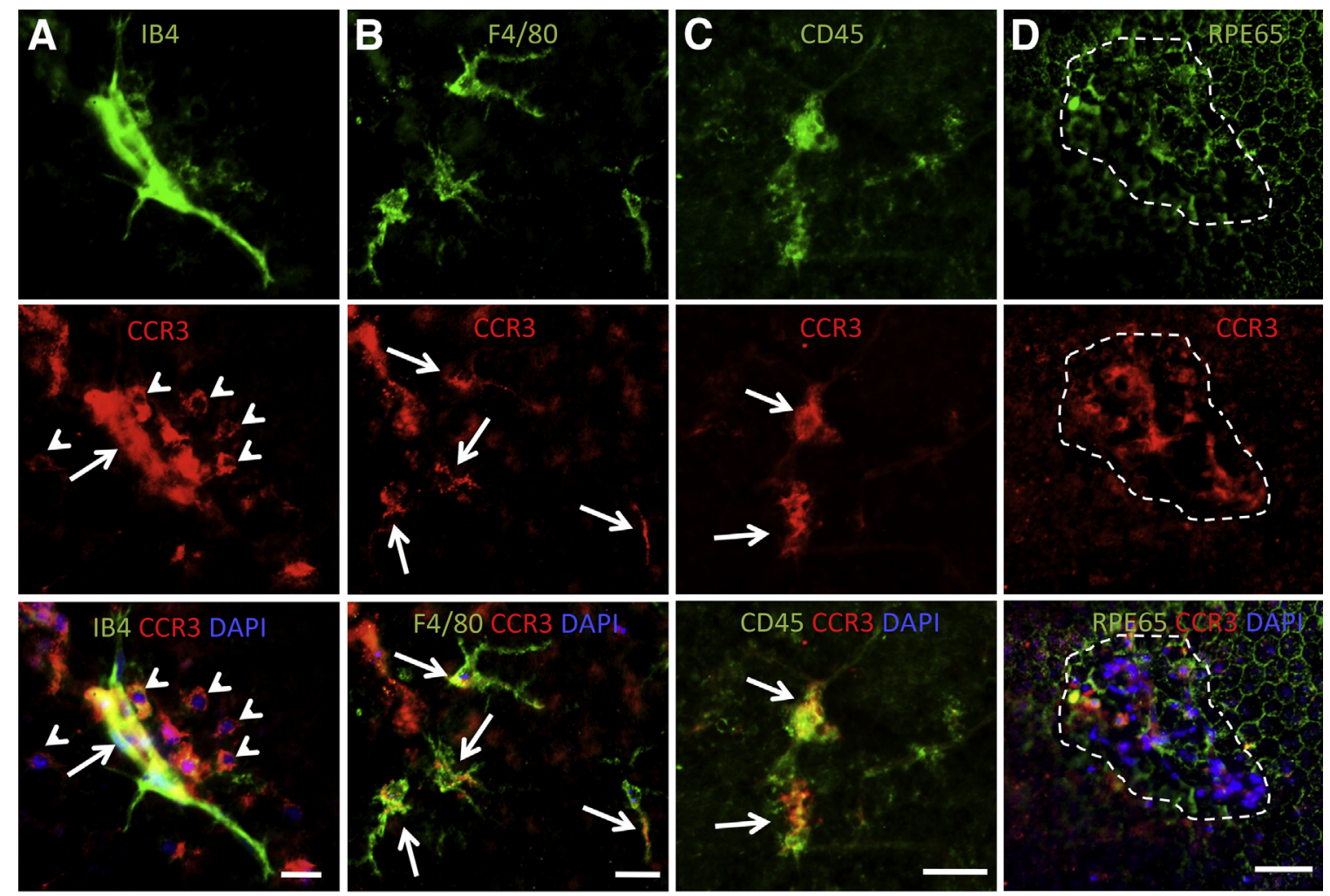

$\mathbf{E}$
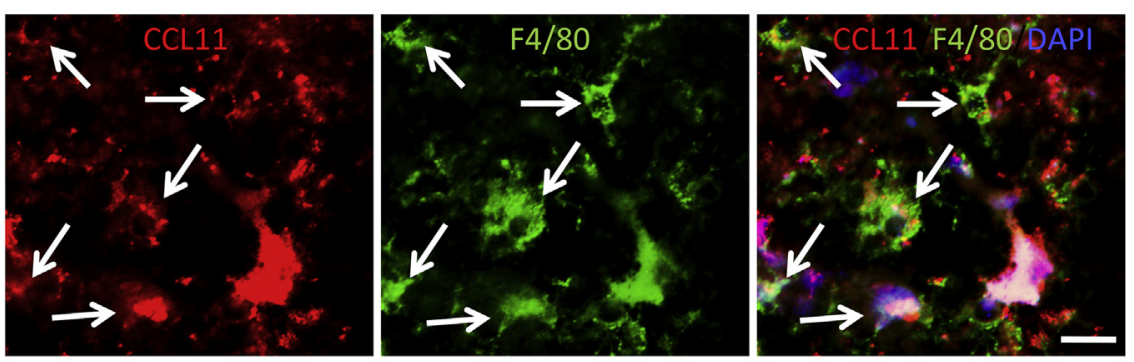

$\mathbf{F}$
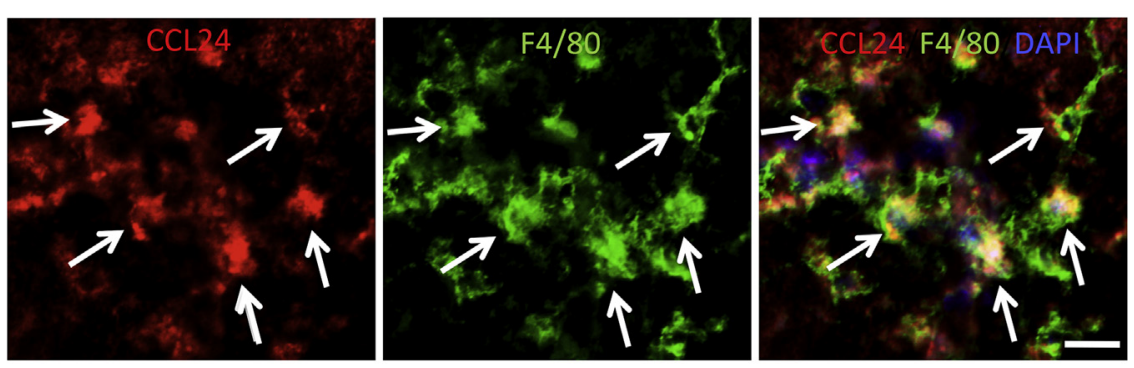

G

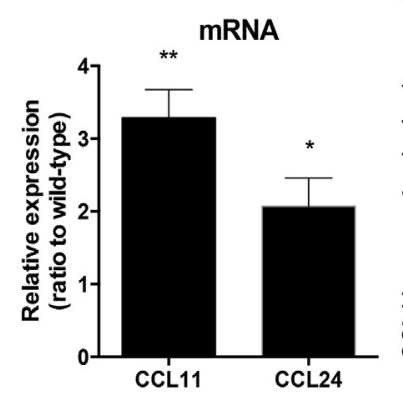

H
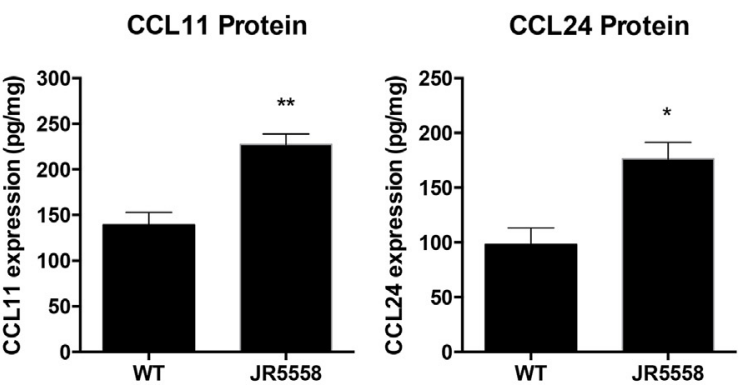
were dilated with topical tropicamide $(1 \%)$. Laser photocoagulation was performed using a diode laser $(680 \mathrm{~nm} ; 210$ $\mathrm{mW}$ of power, 100-ms duration, 100-m spot diameter; Keeler Ltd., Windsor, UK) under direct vision using a handheld cover slide as a contact lens. Lesions were localized to the 2, 10, and 6 o'clock positions of the posterior pole of the retina in both eyes. These laser settings consistently generate a subretinal gas bubble that strongly correlates with laser-induced rupture of the Bruch membrane and successful induction of CNV. Only lesions in which a bubble formed were included in the analysis. Daily oral dosing of 2 to 30 $\mathrm{mg} / \mathrm{kg}$ CCR3 antagonists and $20 \mathrm{mg} / \mathrm{kg}$ of the VEGF receptor (VEGFR)-2 inhibitor pazopanib (GlaxoSmithKline) was started 1 day before the induction of $\mathrm{CNV}$ by laser photocoagulation and continued for 15 days. Fluorescein angiography (FFA) using a Genesis small animal fundus camera (Kowa, Tokyo, Japan) was conducted at 1 and 2 weeks after the induction of CNV. CNV lesion size was quantified by digital image analysis of the mean area of hyperfluorescence per lesion during the early-phase FFA (90 seconds after the injection of $0.2 \mathrm{~mL}$ of $2 \%$ fluorescein sodium solution; Bausch \& Lomb). Eyes were excluded if there was significant cataract or keratopathy that could have affected laser energy delivery or angiography. All dosing was done in a masked fashion.

\section{Treatment of Spontaneous CNV in JR5558 Mice}

JR5558 mice, ${ }^{16}$ which spontaneously generate CNV lesions, were treated by i.p. injection with various amounts $(25$ to $100 \mu \mathrm{g}$ per injection) of a rat anti-mouse VEGFR2-blocking antibody (MAB4431; R\&D Systems, Minneapolis, $\mathrm{MN}$ ) or a purified rat nonimmune, isotype-matched control $\mathrm{IgG}_{2 \alpha}$ antibody (R\&D Systems) starting from postnatal day 14 (P14) for a total of 10 doses in 11 days. CNV development was analyzed by FFA 24 hours after the administration of the last dose, on P25. Mice were treated with various concentrations of the CCR3 antagonist GW766994X by 2 to $30 \mathrm{mg} / \mathrm{kg}$ i.p. injection or 1 and 10 $\mathrm{mg} / \mathrm{mL}$ eye drop starting at $\mathrm{P} 14$ for a total of 12 days. CNV development was analyzed by FFA 24 hours after the administration of the last dose, on P26. For experiments using neutralizing antibodies against CCR3 $(1 \mu \mathrm{g}$ per injection) and its ligands eotaxin-1/CCL11 $(1 \mu \mathrm{g}$ per injection) and eotaxin-2/CCL24 (5 $\mu \mathrm{g}$ per injection), antibodies (all from R\&D Systems) were delivered by intravitreal injection on P24 and P31, and FFA was performed on P30 and P37. For study of the combination effects of $100 \mu \mathrm{g}$ per injection of anti-VEGFR2 antibody (R\&D Systems) and $30 \mathrm{mg} / \mathrm{kg}$ GW766994X, mice were treated by i.p. injection with each material alone or in combination starting from P14, for a total of 10 doses in 11 days. CNV development was analyzed by FFA 24 hours after the administration of the last dose, on P25. For experiments exploring the effects of VEGF-A and CCR3 antagonism on vascular permeability in established CNV lesions, JR5558 mice were treated for 2 days after the development of CNV lesions, on P24 and P25, by i.p. injection with anti-VEGF2 antibody $100 \mu \mathrm{g}$ once daily, GW766994X $8 \mathrm{mg} / \mathrm{kg}$ twice daily, or a combination. FFA analysis was performed on P26. To study the effects of ocular versus systemic administration of CCR 3 antagonists, mice were treated with an eye-drop formulation of GW766994X (10 mg/mL twice daily for 12 days) or intravitreal injection of anti-CCR3 antibody $(1 \mu \mathrm{g}$ per injection on P24 and P31) to the right eye only; the contralateral eye received the corresponding vehicle control. All dosing was performed in a masked fashion.

\section{FFA and Image Analysis of CNV Lesions in Mice}

The pupils of mice were dilated with phenylephrine hydrochloride $2.5 \%$ and tropicamide $1 \%$, and $2 \%$ fluorescein sodium (at $10 \mathrm{~mL} / \mathrm{kg}$ body weight) diluted in water was administered by i.p. injection. A Genesis-Df fundus camera (Kowa) was used for obtaining fluorescein angiograms at the early (90 seconds after fluorescein injection) and late (7 minutes postinjection) phases of dye transit. At the early phase, the vasculature of CNV tissue is clearly defined by the intravascular fluorescein dye. At the late phase, extravascular fluorescein is evident as patches of hyperfluorescence. To quantify CNV area, ImageJ software version 1.46r (NIH, Bethesda, MD; http://imagej.nih.gov/ij) was used for measuring the areas of hyperfluorescence in latephase FFA images. For determining the number of spontaneous CNV lesions per eye in the JR5558 mice, early-phase FFA images with the best coverage of the posterior pole (with the

\footnotetext{
Figure 1 CCR3 and its ligands are expressed in the spontaneous choroidal neovascularization (CNV) lesions of JR5558 mice. A: CCR3 (anti-rabbit Alexa Fluor 594, red) is expressed in the neo-vessels (fluorescein isothiocyanate-IB4, green) of the CNV (arrows) and in nonvascular cells associated the CNV (arrowheads) in eyes of JR5558 mice. B: The CCR3-expressing, nonvascular cells around the CNV are macrophages (F4/80, arrows, anti-rat Alexa Fluor 488, green). C: Some CNV-associated leukocytes (CD45, arrows, streptavidin Alexa Fluor 488, green) also express high levels of CCR3. D: There is no detectable CCR3 staining on the retinal pigment epithelium (RPE65, streptavidin Alexa Fluor 647, pseudo-green) directly under or around the CNV lesion (dotted line), whereas the lesion itself is highly positive for CCR3 (red). Note that the positive CCR3 staining is atop the RPE layer; compare RPE65 with CCR3. E and F: CC chemokine ligand (CCL)-11 (anti-goat Alexa Fluor 594, red) and CCL24 (anti-rabbit Alexa Fluor 594, red) are expressed by macrophages (F4/80, green, arrows) around the CNV (note that some ligands are not associated with cells and likely bind to the extracellular matrix). Animals at postnatal day 30 (P30) were used for A-D and P20 mice were used for the staining in E and F. G: Real-time PCR analyses of the relative expression of CCL11 and CCL24 mRNA show that both ligands are expressed at higher levels in the RPE/choroid complex of JR5558 mice compared with wild-type (WT) controls at P20, during the active phase of spontaneous CNV development. H: Protein levels of CCL11 and CCL24 were measured by enzyme-linked immunosorbent assay in the RPE/choroid complex in both WT and JR5558 mice at P20. Data are expressed as means \pm SEM. $n=\geq 3$ eyes per group $(\mathbf{G}) ; n=12(\mathbf{H}, \mathrm{CCL} 11) ; n=8(\mathbf{H}, \mathrm{CCL} 24) .{ }^{*} P<0.05,{ }^{* *} P<0.01$ versus levels in wild-type control. Scale bars $=20 \mu \mathrm{m}$.
} 
optic disk at the center) were used. The permeability of each $\mathrm{CNV}$ lesion was determined by subtracting the hyperfluorescent area in early-phase FFA imaging from that of latephase imaging of the same lesion using ImageJ software, and the permeability data from all detectable CNV lesions from each eye were collected for calculating the mean permeability per CNV per eye. All FFA image analyses were performed by masked investigators (N.N., M.J., K.I.-N., S.J.R.).

\section{Whole-Mount Eyecup Staining for CNV Lesions in Mice}

Twenty-four hours after final FFA, eyes were enucleated and fixed with $4 \%$ paraformaldehyde in phosphate-buffered saline for 3 hours at $4{ }^{\circ} \mathrm{C}$. Eyecups with or without the retina removed were blocked in buffer containing 0.3\% Triton X-100 and 5\% fetal bovine serum in phosphate-buffered saline (blocking buffer) for 1 hour at room temperature, then incubated overnight at $4^{\circ} \mathrm{C}$ with fluorescein isothiocyanate (FITC)-isolectin B4 (1:200 dilution in blocking buffer; Vector, Burlingame, CA) alone or in combination with primary antibodies (all at 1:100 dilution), namely: anti-F4/80, anti-CD45, anti-CCR3 (all from Abcam, Cambridge, MA), anti-CCL11 (R\&D Systems), and anti-CCL24 (Antibodies Online, Atlanta, GA). After three washes, appropriate secondary antibodies, namely anti-rat Alexa Fluor 488, anti-rat Alexa Fluor 594, anti-rabbit Alexa Fluor 594, anti-goat Alexa Fluor 594, streptavidin Alexa Fluor 488, or streptavidin Alexa Fluor 647 (all 1:300 dilution in blocking buffer; Life Technologies, Carlsbad, CA), were added and specimens incubated at room temperature for 2 hours. After five washes, the specimen was mounted with medium containing DAPI and viewed with an epifluorescence BX51 microscope (Olympus, Essex, UK) with a Retiga SRV camera (QImaging, Surrey, BC, Canada). The microscope was equipped with the following objectives and numerical apertures: $4 \times, 0.16 ; 10 \times, 0.40 ; 20 \times, 0.75 ; 40 \times, 0.90 ; 60 \times, 1.35$ (oil), and ImagePro version 6.2 (Media Cybernetics, Rockville, $\mathrm{MD)}$ was used for image acquisition.

For morphometric analysis of $\mathrm{CNV}$, the total number of CNV lesions on images showing FITC-isolectin B4 staining of the entire flat-mount eyecup (RPE side up) was counted. For CNV area per eye, the same FITC-isolectin B4 staining image was flattened, background was subtracted with a rolling ball radius of 50 pixels, a binary image was generated through thresholding, and the number of positive pixels was counted for the entire eyecup (pixel area; ImageJ software). For calculation of the mean macrophage area per field, areas of the eyecup with CNV (FITC-isolectin B4-positive) were chosen. The F4/80 staining image of the same area was flattened, a binary image and mask were generated by thresholding, and the F4/80-positive pixels were counted for the entire field. For selected images, the mask was inverted and overlaid onto the original image to highlight the stained macrophages (ImageJ software). To calculate the mean macrophage area per CNV lesion, the total macrophage area per field was divided by the total number of CNV lesions (based on FITC-isolectin staining) from the corresponding fields. All morphometric analyses were performed in a masked fashion (M.J.).

\section{Treatment of Laser-Induced CNV in Cynomolgus Monkeys}

Cynomolgus monkeys were orally dosed three times daily with vehicle or the CCR3 antagonist GW782415X at $3 \mathrm{mg} /$ $\mathrm{kg}$ or $20 \mathrm{mg} / \mathrm{kg}(5 \mathrm{~mL} / \mathrm{kg})$ for 29 days, with the first day of dosing 1 day before laser photocoagulation. In a separate experiment, a suspension containing 10\% w/v GW776994X (dosed on days 8 and 22) or a sustained-release device (implanted on day 1) releasing specified daily amounts of GW776994X was instilled into the eye and compared against a vehicle formulation or a blank implant (no CCR3 antagonist loaded). An additional animal cohort was dosed topically with $50 \mu \mathrm{L}$ of $10 \mathrm{mg} / \mathrm{mL}$ GW776994X twice daily for 29 days. Before intravitreal injections, the eyes were anesthetized using a topical anesthetic $(0.5 \%$ proparacaine; Bausch \& Lomb), cleaned with $1 \%$ povidone iodine (prepared with sterile saline and $10 \%$ povidone iodine; Bausch \& Lomb), and rinsed with sterile saline. The periorbital region was cleaned with a dilute, $1 \%$ povidone iodine solution. Doses were administered by intravitreal injection using a 1-cc syringe and a 30-gauge (injections) or 25-gauge (implants) needle. Injections were given into the inferior aspect of the eye. A topical antibiotic (tobramycin; Alcon Laboratories, Fort Worth, TX) was instilled in each eye after the intravitreal injection.

For laser photocoagulation, the macula of each eye was targeted with a 532-nm diode green laser (OcuLight GL; Iridex Corp. Inc., Mountain View, CA) using a slit-lamp delivery system and a Kaufman-Wallow plano fundus contact lens (Ocular Instruments Inc., Bellevue, WA). Animals were anesthetized and nine areas symmetrically placed in the macula of each eye. The laser parameters included a 75micron spot size and 0.1-second duration. The power setting was assessed by the ability to produce a blister and a small hemorrhage. If hemorrhage was not observed with the first laser treatment, a second laser spot was placed adjacent to the first following the same laser procedure, except at a higher wattage. For areas not adjacent to the fovea, the initial power setting was $500 \mathrm{~mW}$; if a second spot was placed, the power was set to $650 \mathrm{~mW}$. For the area adjacent to the fovea, the power setting was $400 \mathrm{~mW}$ for initial treatment and $550 \mathrm{~mW}$ for secondary treatment. At the discretion of the retinal surgeon, power settings were further adjusted based on observations at the time of photocoagulation.

FFA was conducted on days 14, 21, and 28 after laser photocoagulation. Animals were fasted for at least 2 hours before being anesthetized, and the eyes were dilated with a mydriatic agent. Animals were intubated due to the possibility of emesis after the fluorescein injection. Images were taken at the start and end of the i.v. fluorescein injection. After fluorescein injection, a rapid series (approximately from dye appearance through 35 seconds) of stereo images 
of the posterior pole were taken of the right eye, followed by a stereo pair of the posterior pole of the left eye. Additional stereo pairs of both eyes were taken at approximately 1 to 2 and 5 minutes after fluorescein injection. Between approximately 2 and 5 minutes after fluorescein injection, nonstereoscopic images of two mid-peripheral fields (temporal and nasal) of each eye were taken. FFA images were evaluated according to the following grading system, which has been described previously ${ }^{17}$ : grade I, no hyperfluorescence; grade II, hyperfluorescence without leakage; grade III, early or mid-transit hyperfluorescence and late leakage; grade IV, bright early or mid-transit hyperfluorescence and late leakage outside the borders of the treated area. Because grade IV lesions most closely resemble CNV seen in various human retinal disorders, including AMD, the prevalences of grade IV lesions were compared between groups. This analysis was performed by a masked observer.

\section{Real-Time PCR and Protein Analysis}

Mouse eyes were stored in RNAlater (InvitroGen, Grand Island, NY) until RNA was extracted from the retina and the RPE/choroid complex using the RNeasy Mini Kit (Qiagen, Valencia, CA). Complementary DNA synthesis was performed using the RT2 Easy First Strand Kit (Qiagen), and real-time PCR was conducted using the TaqMan gene expression assays for CCL11 and CCL24 (Applied Biosystems, Warrington, UK). Expression levels of target genes were determined by the relative quantification method using $\beta$-actin as an endogenous control and plotted as a ratio to that of the wild-type control. For enzyme-linked immunosorbent assay, the retina and the RPE/choroid complex were harvested into radioimmunoprecipitation assay lysis buffer (Sigma-Aldrich, Dorset, UK), supplemented with protease inhibitors and sonicated. The lysate was centrifuged at $21,130 \times g$ for 10 minutes at $4^{\circ} \mathrm{C}$, and CCL11 and CCL24 levels in the supernatant were determined with enzyme-linked immunosorbent assay kits (R\&D Systems) according to the manufacturer's protocol. The tissue sample concentration was calculated from a protein standard curve.

\section{Measurement of Plasma and Ocular Tissue Levels of CCR3 Inhibitors}

Blood from treated animals was collected into tubes containing $\mathrm{K}_{2}$ EDTA, using an appropriate sampling method, and placed on wet ice after collection. Plasma was collected after centrifugation. Plasma and aqueous humor samples were extracted using an analytical method based on liquidliquid extraction. For ocular tissues, eyes were enucleated from euthanized animals and ocular tissues (iris-ciliary body, RPE/choroid punch, retina punch, remainder of choroid/ RPE, remainder of retina, and vitreous humor) collected using a frozen-tissue collection technique. The "punch" samples were collected using an 8-mm biopsy punch. The punch samples were taken from the posterior portion of the globe, temporal to the optic nerve. Individually collected ocular tissues were extracted twice using a protein precipitation method. Extracted samples were quantitated for parent compound using liquid chromatography-tandem mass spectrometry against known standard curves. The liquid chromatography-tandem mass spectrometry system consisted of an Acquity ultra high-performance liquid chromatography system (Waters, Milford, MA) and an API 4000 triple quadrupole mass spectrometer (AB Sciex, Framingham, MA) operating with Analyst software version 1.4.2 (AB Sciex). A high-performance liquid chromatography method utilizing an ultra-high-performance liquid chromatography $\mathrm{C}_{18}$ column $\left(50 \times 2.1 \mathrm{~mm} \mathrm{HSS} \mathrm{C}_{18}, 1.8\right.$ $\mu \mathrm{m}$; Waters) was used for separating the parent molecule from endogenous plasma components. The mass spectrometer was operated in the positive turbo ionspray using a multiple reaction monitoring scan mode. The computer systems that were used for acquiring and quantifying data in this study included Analyst version 1.4.2 (AB Sciex) and an internal GlaxoSmithKline laboratory information management system (SMS2000 version 2.3).

\section{Statistical Analysis}

For the laser-induced CNV model in the mouse, the CNV area was quantified using FFA, and each individual laserinduced CNV lesion was analyzed as an individual data point (n). For the JR5558 spontaneous CNV model, total $\mathrm{CNV}$ area per eye and number of CNV lesions per eye were quantified using FFA, and each individual eye was analyzed as an individual data point $(n)$. For the laserinduced CNV model in the monkey, the CNV was graded using FFA, and each individual eye was analyzed as an individual data point $(n)$. Data analysis for the laserinduced CNV model in the monkey was conducted using a mixed-effects model on the square root of the counts plus 1 , followed by the Tukey test for multiple comparisons. All other data were analyzed using one-way analysis of variance followed by the Fisher post hoc test or two-tailed unpaired $t$-test for comparing data between different test groups and time points (SPSS version 17; SPSS Inc., Chicago, IL). $P<0.05$ was considered statistically significant. Data are expressed as means \pm SEM, unless otherwise noted. All experiments and data analysis were performed in a masked fashion (N.N., M.J., K.I.-N., S.J.R.), and sample size was determined based on prior experiments using the same models.

\section{Results}

CCR3, CCL11/Eotaxin-1, and CCL24/Eotaxin-2 Are Expressed at Spontaneous CNV Lesions in JR5558 Mice

The JR5558 mouse model of spontaneous CNV is a newly described model that mimics the progression of wet AMD in humans better than do laser photocoagulation models. ${ }^{16}$ 

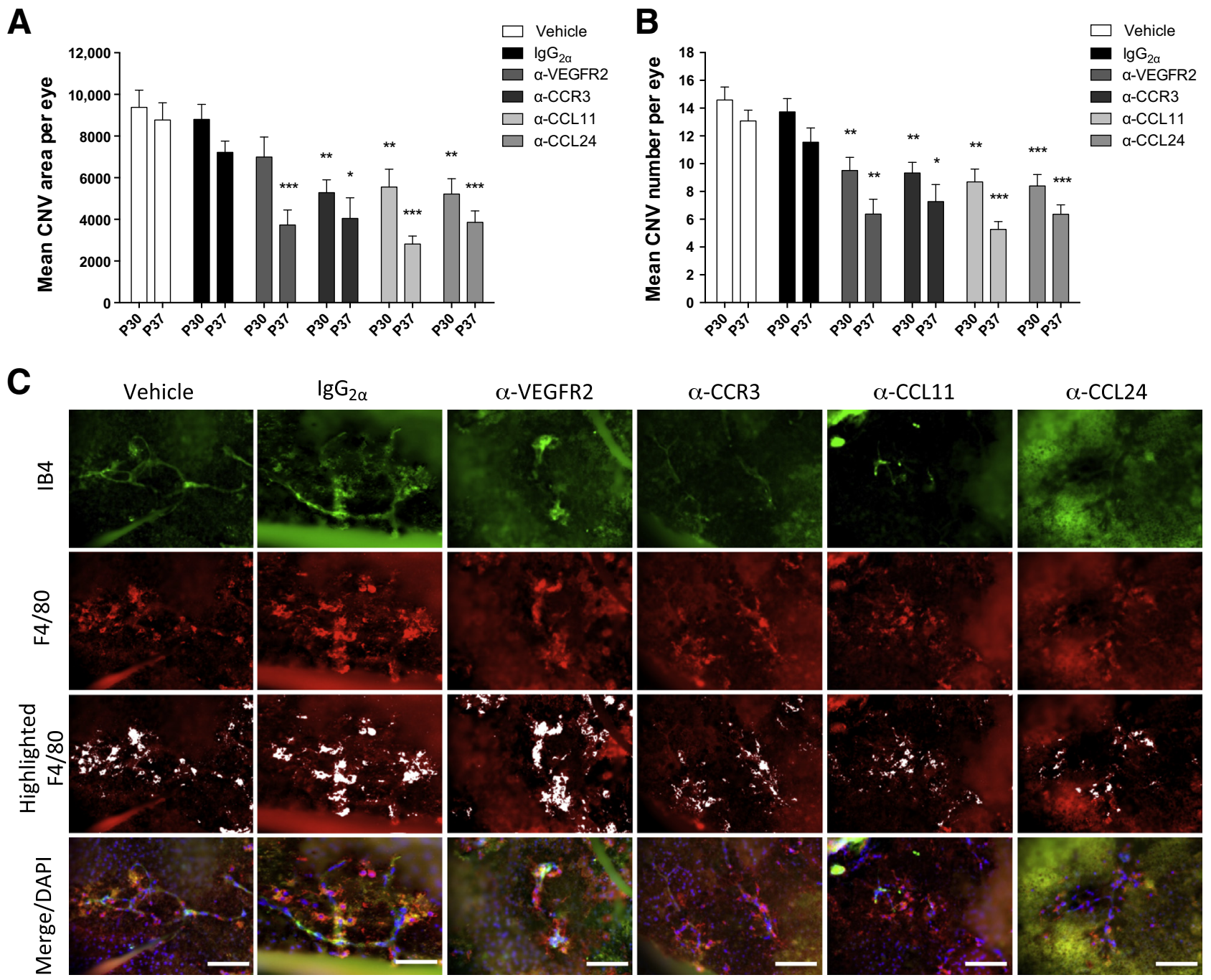

Figure 2 Intravitreal injections of neutralizing antibodies against CCR3, CC chemokine ligand (CCL)-11, CCL24, or vascular endothelial growth factor receptor (VEGFR)-2 suppress spontaneous choroidal neovascularization (CNV) development in JR5558 mice. A and B: Average CNV area and lesion number per eye are significantly reduced by intravitreal injection with anti-CCR3 $(1 \mu \mathrm{g})$, anti-CCL11 $(1 \mu \mathrm{g})$, or anti-CCL24 $(5 \mu \mathrm{g})$ at both time points tested, with therapeutic efficacy comparable to (if not better than) that of anti-VEGFR2 ( $5 \mu \mathrm{g}$ per injection) antibody treatment, based on fluorescein angiography (FFA) analysis. C: Staining for neovessels (fluorescein isothiocyanate-IB4, green) and macrophages (F4/80, anti-rat Alexa Fluor 594, red, and highlighted in white by using ImageJ software in separate panels) in eyes from different treatment groups shows a trend of a reduction in macrophage recruitment after treatments with anti-CCR3, anti-CCL11, and anti-CCL24 compared with both vehicle and $\mathrm{IgG}_{2 \alpha}$ controls. Data are expressed as means \pm SEM. $n=10$ to 15 eyes per group. ${ }^{*} P<0.05,{ }^{* *} P<0.01$, and ${ }^{* * *} P<0.001$ versus IgG (1 $\mu$ g per injection) control (unpaired $t$-test, corrected for multiple comparisons using the Holm-Šídák method). Scale bars $=20 \mu \mathrm{m}$.

Because this was the first use of the JR5558 mouse for a study of CCR3 antagonism, we first characterized the expression of CCR3, CCL11, and CCL24 in the eyes of JR5558 mice. Immunohistological analysis revealed that CCR3 expression was primarily localized to CNV lesions (Figure 1A). CCR3-positive cells were closely associated with isolectin B4-stained neovessels and colabeled nonvascular cells, including leukocytes and, to some extent, macrophages, but not RPE cells (Figure 1, A-D). Little or no CCR3 expression was detected in areas of the eyecups without CNV. Real-time PCR analysis demonstrated that mRNA expression levels of CCR3 in the RPE/choroid were comparable between the JR5558 mice and wild-type controls (unpublished data).
The CCR3 ligands CCL11 and CCL24 were detected on macrophages associated with the CNV lesion (Figure 1, E and $\mathrm{F}$ ), indicating that macrophages may be the main source of CCR3 ligands in the spontaneous CNV model. Indeed, both real-time PCR and enzyme-linked immunosorbent assay analysis of the RPE/choroid complex revealed significantly higher levels of CCL11 and CCL24 expression in the JR5558 eyes compared with agematched, wild-type controls (Figure 1, G and H). Expression of these ligands in the retina was not significantly different between JR5558 mice and controls (unpublished data), confirming that increased levels of CCL11 and CCL24 were localized to the subretinal space and the RPE/ choroid complex. 
A

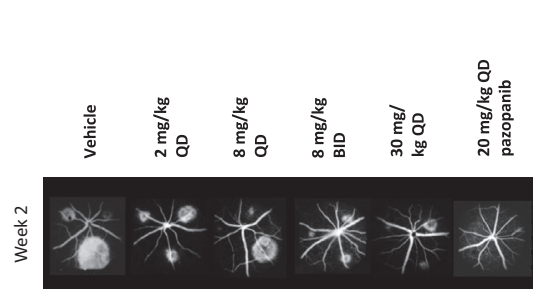

B

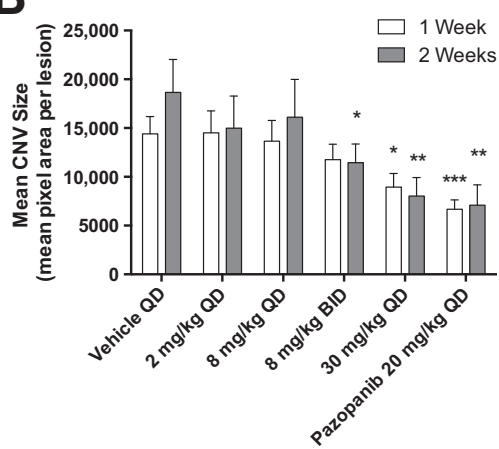

C

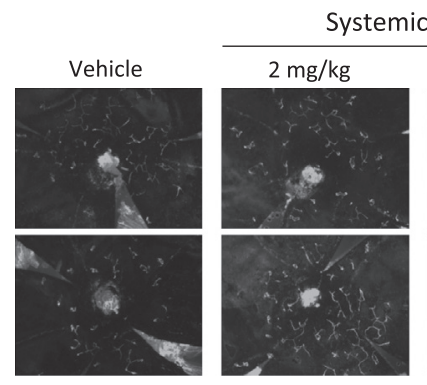

D

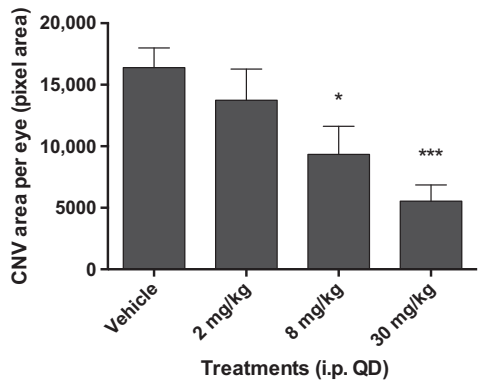

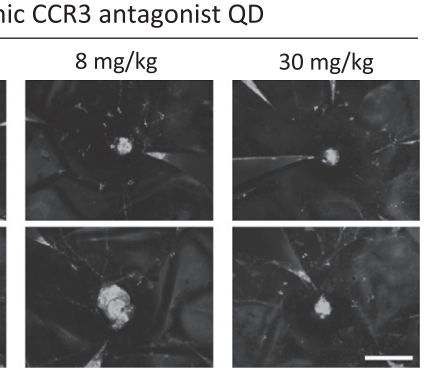

E

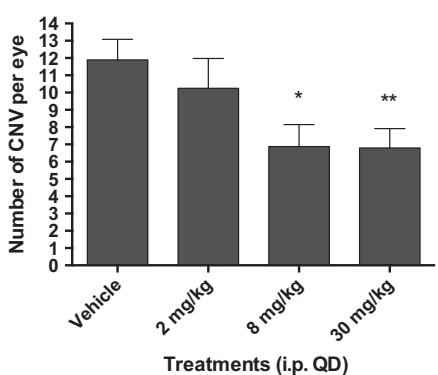

Figure 3 Systemic administration of the CCR3 antagonist GW766994X attenuates laser-induced and spontaneous choroidal neovascularization (CNV) in mice. A: Representative fluorescein angiography (FFA) images from all treatment groups at the 2-week time point. B: Systemic GW766994X dose-dependently suppresses laser-induced CNV. Animals were dosed once daily (QD) or twice daily (BID) orally 1 day before laser injury, with treatment continuing for 14 days. C: Representative CNV staining (fluorescein isothiocyanate-IB4, white vessels) of eye cups (retina removed; optic nerve at center of image) from JR5558 mice shows reduction in CNV in GW766994X-treated mice. Images are from two individual animals from each treatment group from the experiment shown in $\mathbf{D}$ and $\mathbf{E}$. $\mathbf{D}$ and $\mathbf{E}$ : Systemic i.p. dosing with CCR3 antagonist GW766994X significantly suppresses spontaneous CNV development in JR5558 mice. Both the average CNV area per eye (D) and number of lesions per eye (E) are reduced by systemic GW766994X treatment in a dose-dependent manner. Data are expressed as means \pm SEM (E). $n=76$ to 78 individual laser burns per group (B); $n=8$ to 10 eyes per group (E). ${ }^{*} P<0.05,{ }^{* *} P<0.01$, and ${ }^{* *} P<0.001$ versus vehicle control. Scale bar $=1 \mathrm{~mm}(\mathbf{C})$.
Ocular Neutralization of CCR3 and Its Ligands Inhibits Spontaneous CNV Development in JR5558 Mice

To determine the roles of CCL11 and CCL24 in CNV and to assess the effects of CCR3 pathway-neutralizing antibodies on spontaneous $\mathrm{CNV}$ lesions, intravitreal neutralizing antibodies against CCR3, CCL11, or CCL24 were administered in JR5558 mice at P24 and P31. CNV area and lesion number were determined by FFA at P30 and P37 in live animals. Neutralization of CCR3, CCL11, or CCL24 significantly inhibited the $\mathrm{CNV}$ area per eye (to $59 \%$ to $63 \%$ of IgG controls at P30, $P<0.01$; and $39 \%$ to $56 \%$ of IgG controls at P37, $P<0.05$ ) and the number of lesions per eye (61\% to $68 \%$ of IgG controls at $\mathrm{P} 30, P<0.01$; and $46 \%$ to $63 \%$ of $\mathrm{IgG}$ controls at $\mathrm{P} 37$, $P<0.05$ ) (Figure 2, A and B). For comparison, anti-VEGFR2 antibody, a positive control, inhibited $\mathrm{CNV}$ area to $51 \%$ of $\mathrm{IgG}$ control at P37 $(P<0.001)$ and lesion number to $53 \%$ of $\operatorname{IgG}$ control at P37 $(P<0.01)$ (Figure $2, \mathrm{~A}$ and $\mathrm{B})$.

Reduction in the staining of the new vessels was observed in eyes that had been treated with neutralizing antibodies against VEGFR2, CCR3, CCL11, or CCL24 (Figure 2C). Reduced macrophage staining was observed around the
CNV lesions in the eyes treated with anti-CCR3, antiCCL11, and anti-CCL24 antibodies, but not in those treated with anti-VEGFR2 (Figure 2C).

Systemic CCR3 Antagonism with GW766994X Limits the Development of Both Laser-Induced CNV and Spontaneous CNV in Mice

Although CCR3 blockade has shown excellent promise in mouse models of $\mathrm{CNV}$, variable efficacy has been seen with different treatment strategies and different means of inducing CNV. ${ }^{1,15,18}$ We therefore tested the novel CCR3 antagonist GW766994X in both the mouse laser-induced CNV model and the JR5558 spontaneous CNV mouse model. The laserinduced CNV model is a well-described wound-healing response in which the $\mathrm{CNV}$ naturally resolves in about 21 days after induction. ${ }^{19}$ In contrast, the JR5558 mouse is a genetic model of spontaneous $\mathrm{CNV}$, in which the mice develop bilateral, multifocal, VEGF-dependent CNV, driven in part by inflammatory processes; as in wet AMD, the CNV does not naturally regress. ${ }^{16}$ 

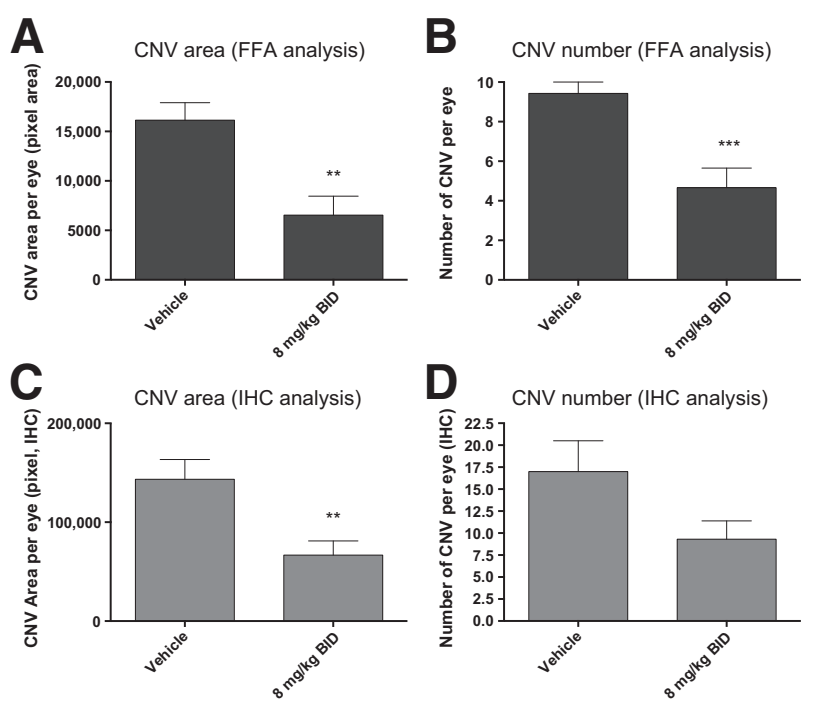

Figure 4 Twice-daily (BID) dosing of GW766994X results in better efficacy in inhibiting spontaneous choroidal neovascularization (CNV) development. Inhibition of CNV development in JR5558 mice is seen on fluorescein angiography (FFA) analysis (A and B) and by immunohistochemical (IHC) analysis of the eye cups (C and $\mathbf{D})$. Data are expressed as means \pm SEM. ${ }^{* *} P<0.01,{ }^{* * *} P<0.001$ versus vehicle control. $n=14$ to 15 eyes (A and $\mathbf{B}) ; n=8$ eyes ( $\mathbf{C}$ and $\mathbf{D})$.

In the laser photocoagulation model, GW766994X was orally dosed starting 1 day before $\mathrm{CNV}$ induction and continuing for 14 days. A $30-\mathrm{mg} / \mathrm{kg}$ dose administered once daily led to a significant decrease in the area of $\mathrm{CNV}$ at day 7 (62\% of vehicle control, $P<0.05)$ and day $14(43 \%$ of control, $P<0.01$ ), based on fundus FFA analysis (Figure 3, A and B). For comparison, a once-daily oral dose of $20 \mathrm{mg} /$ $\mathrm{kg}$ of a VEGFR inhibitor, the small-molecule tyrosine kinase inhibitor pazopanib, ${ }^{20}$ significantly reduced $\mathrm{CNV}$ area at days 7 and 14 (46\% and 38\% of control, respectively; $P<0.01$ for both) (Figure 3B). A lower oral dose of GW766994X, $8 \mathrm{mg} / \mathrm{kg}$, also significantly reduced CNV area at day 14 (61\% of control, $P<0.05)$, but only when administered twice daily, and no significant reduction was observed at day 7 (Figure 3B).

In the JR5558 mice, spontaneous CNV lesions initiate at about P12, and new lesions continue to form thereafter. ${ }^{16}$ Treatment with GW766994X was therefore started at P14 and continued for 12 days, at which point animals were examined by FFA, with i.p. dosing used instead of oral gavage due to the young age of the animals. Treatment with i.p. GW766994X limited CNV development in this model as well, as shown by immunohistochemical analysis of isolated eyecups (retina removed) (Figure 3C) and by FFA determination of both total lesion area (Figure 3D) and the number of CNV lesions in the eyes (Figure 3E). With the 8$\mathrm{mg} / \mathrm{kg}$ daily dose, $\mathrm{CNV}$ area and lesion number were $57 \%$ and 58\% of control measures, respectively $(P<0.05$ for both), and with the $30-\mathrm{mg} / \mathrm{kg}$ daily dose, CNV area and lesion number were $34 \%$ and $57 \%$ of control measures, respectively $(P<0.001$ and $P<0.01$, respectively). The 2-mg/kg daily dose did not yield a significant reduction in $\mathrm{CNV}$ area or lesion number.

When comparing the oral and i.p. doses of GW766994X in the two models, it must be noted that systemic exposure is approximately 3.8 -fold less with oral administration (mean plasma concentration at 0.5 hour, $643 \pm 129 \mathrm{ng} / \mathrm{mL}$ ) compared with i.p. dosing (mean plasma concentration at 0.5 hour, $2470 \pm 901 \mathrm{ng} / \mathrm{mL}$ ). Because GW766994X has a predicted circulating half-life of about 1.9 hours in the mouse (unpublished data), and twice-daily oral dosing of GW766994X at $8 \mathrm{mg} / \mathrm{kg}$ showed significant inhibition of laser-induced $\mathrm{CNV}$ at day 14, the effect of twice-daily i.p. dosing of GW766994X at $8 \mathrm{mg} / \mathrm{kg}$ on spontaneous CNV was also evaluated in the JR5558 mice. This dosing strategy significantly limited both total $\mathrm{CNV}$ area and total lesion number (to $41 \%$ and $49 \%$ compared with controls, respectively; $P<0.01$ and $P<0.001$, respectively) (Figure 4, A and B). Animals were sacrificed immediately after the completion of FFA, and selected eyecups were processed for $\mathrm{CNV}$ evaluation by semiquantitative immunohistochemical analysis. The results correlated well with the live FFA and showed that $8 \mathrm{mg} / \mathrm{kg} \mathrm{GW766994X} \mathrm{administered}$ twice daily via i.p. injection had a significant effect on the CNV area (47\% of control, $P<0.01$ ), and a strong reduction trend for lesion number per eye was observed (55\% of control, $P=0.08$ ) (Figure 4, C and D).

\section{Systemic GW766994X and VEGFR2 Neutralizing Antibodies Have an Additive Effect in Limiting} Spontaneous CNV in the JR5558 Model

Because anti-VEGF therapies are currently the standard of care for wet AMD, and to further elucidate the potential interaction between VEGF and CCR3 pathways in CNV, we examined the effects of dual treatment with anti-VEGFR2 antibodies and GW766994X in the JR5558 model. In a pilot experiment, systemic i.p. delivery of anti-VEGFR2 (25 to $100 \mu \mathrm{g} /$ injection, once-daily dosing starting at P14 for a total of 10 doses and final FFA analysis at P25) resulted in dose-dependent inhibition of CNV in the JR5558 model (unpublished data). Based on these results, $100 \mu \mathrm{g} /$ injection was selected as an appropriate high-antibody dose for maximum $\mathrm{CNV}$ inhibition in this model. Once-daily i.p. anti-VEGFR2 $(100 \mu \mathrm{g})$ and GW766994X $(30 \mathrm{mg} / \mathrm{kg})$ administered singly significantly reduced CNV area (to $42 \%$ of control for anti-VEGFR2, 44\% for GW766994X; $P<0.01$ for both) and lesion number per eye (to $45 \%$ of control for anti-VEGFR2, 51\% for GW766994X; $P<0.01$ for both) (Figure 5, A and B). Combination treatment significantly reduced both $\mathrm{CNV}$ area and the number of lesions per eye $(P<0.001$ versus control for both $)$ (Figure 5, A and B) and, more importantly, resulted in a significant further reduction in CNV area per eye compared with single treatment with either anti-VEGFR2 or GW766994X ( $P<0.05$ for both) (Figure 5A). These data suggest a small but significant additive effect of systemic 
anti-VEGFR2 and the CCR3 antagonist GW766994X in blocking spontaneous CNV.

\section{Systemic GW766994X Limits Vascular Permeability Associated with CNV in the JR5558 Model}

Because we repeatedly observed a trend of more efficient inhibition of CNV area than lesion number (Figures 3, 4, and 5), CCR3 blockade might suppress the growth and/or

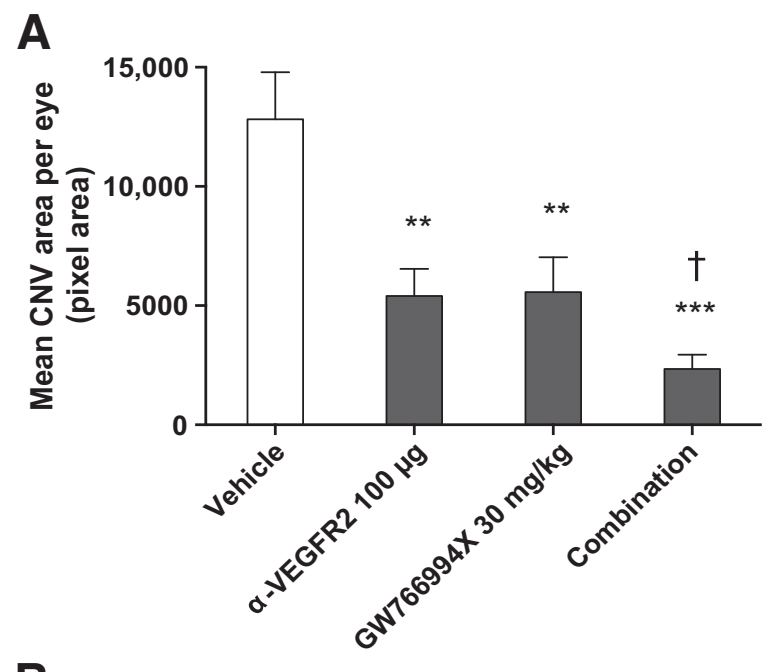

B
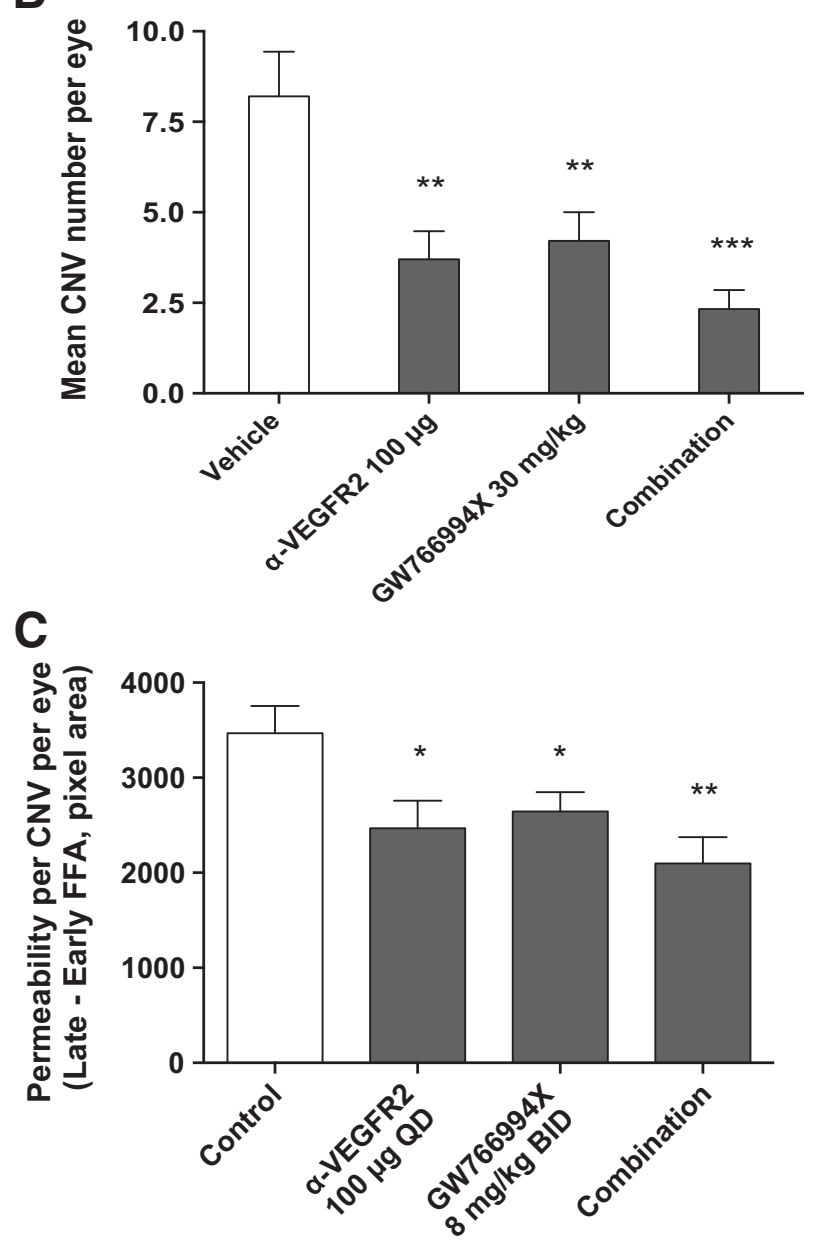

vascular permeability of the CNV lesions-either of which could contribute to lesion size-but have a lesser effect on the initiation on new CNV lesions. One of the major therapeutic effects of anti-VEGF treatment is a reduction in vascular leakage in the CNV lesions. ${ }^{21,22}$ Because CCR3 ligands increase permeability in cultured human coronary artery endothelial cells, ${ }^{23}$ we examined whether CCR3 inhibition might affect vessel permeability. To distinguish between the effects on permeability and CNV growth, a short treatment protocol was used for minimizing the effect of treatment on CNV growth. Animals with established CNV lesions were treated with GW766994X, both alone and in combination with anti-VEGFR2, for only 2 days, at P24 and P25. Injection (i.p.) of anti-VEGFR2, GW766994X, or the combination treatment significantly reduced CNV permeability compared with untreated controls $(P<0.05, P<0.05$, and $P<0.01$, respectively) (Figure $5 \mathrm{C}$ ). Whereas antiVEGFR2 and GW766994X were comparable in reducing CNV permeability (71\% and 76\% of control for anti-VEGFR 2 and GW766994, respectively), combination treatment (60\% of control) was not significantly more effective than either single treatment $(P=0.11$ and 0.36 versus GW766994X alone and anti-VEGFR2 alone, respectively).

Topical CCR3 Antagonism with GW766994 Limits the Development of Spontaneous CNV in the JR5558 Model: Local versus Systemic Effects of CCR3 Antagonism

Because the intravitreal delivery of neutralizing antibodies against CCR3 and its ligands was effective in inhibiting CNV development, the efficacy of topical GW766994X was evaluated using an eye-drop formulation. Corresponding with the previous systemic dosing study (Figure 5), the eye drops were applied starting at P14 and continuing for 12 days, and CNV was evaluated by FFA at P26. Twice-daily eye drops significantly suppressed the average CNV area per eye in a dosedependent manner (to $66 \%$ of vehicle control for $1 \mathrm{mg} / \mathrm{mL}$, $P<0.05$; and $45 \%$ for $10 \mathrm{mg} / \mathrm{mL}, P<0.001$ ), as well as the mean number of spontaneous lesions per eye (to $49 \%$ of vehicle control, $P<0.01$ ) with the $10 \mathrm{mg} / \mathrm{mL}$ eye-drop

\footnotetext{
Figure 5 Combination treatment with systemic anti-vascular endothelial growth factor receptor (VEGFR)-2 antibody and GW766994X has an additive inhibitory effect on choroidal neovascularization (CNV) development and hyperpermeability. A and B: Systemic treatment of JR5558 mice with anti-VEGFR2 antibody, GW766994X CCR3 antagonist, and combination treatment all significantly reduce CNV area and number of lesions per eye, and combination treatment is significantly more effective in reducing CNV area per eye compared with either treatment alone. C: Short-term (2-day) systemic treatment with anti-VEGFR2 antibody, GW766994X, and combination treatment all significantly reduce CNV permeability per lesion per eye compared with control, with permeability defined as early phase fluorescein angiography (FFA) subtracted from late-phase FFA of the same lesion. Data are expressed as means \pm SEM. $n=18$ to 26 eyes per group (C); $n=24$ eyes per group (B). ${ }^{*} P<0.05,{ }^{*} P<0.01$, and ${ }^{* * *} P<0.001$ versus vehicle control; ${ }^{\dagger} P<0.05$ versus both single treatments.
} 
A

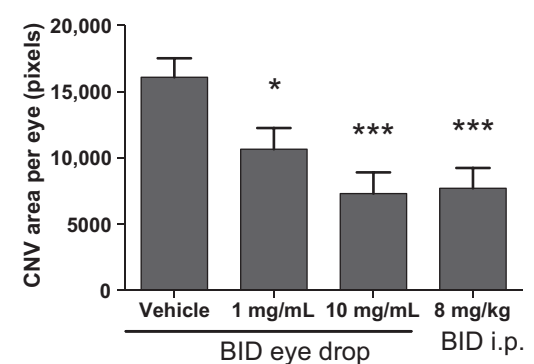

C

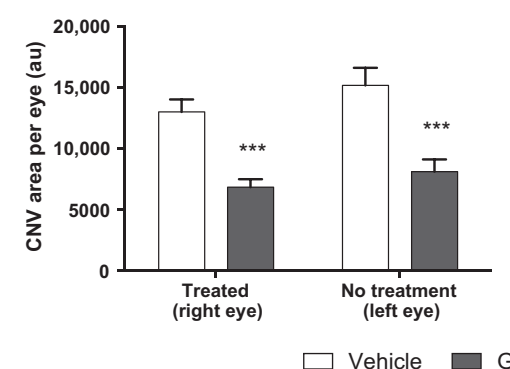

E

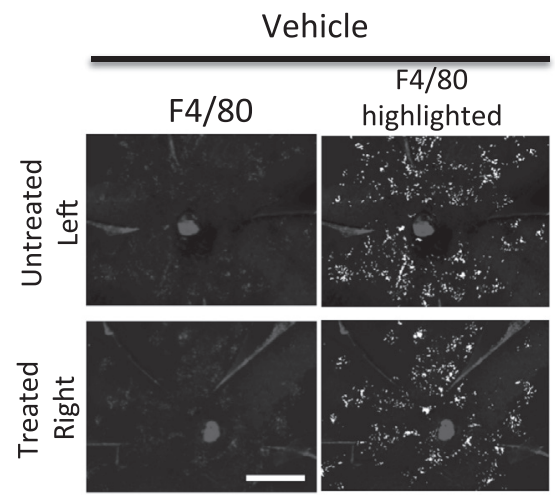

$\mathbf{F}$

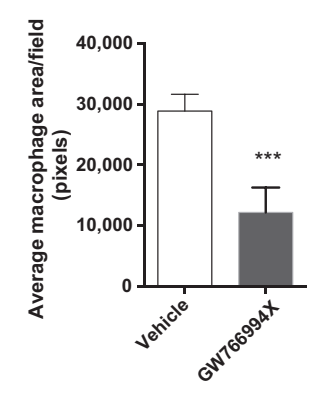

G

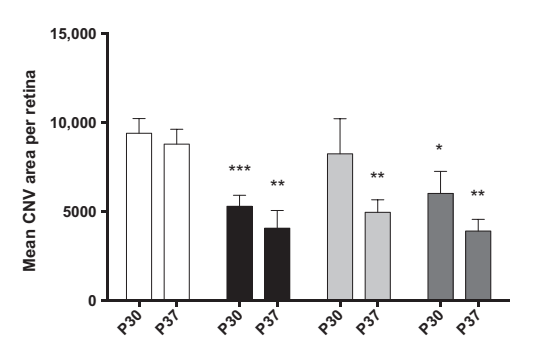

$\square$ Vehicle bilateral

\section{H \\ H}

B

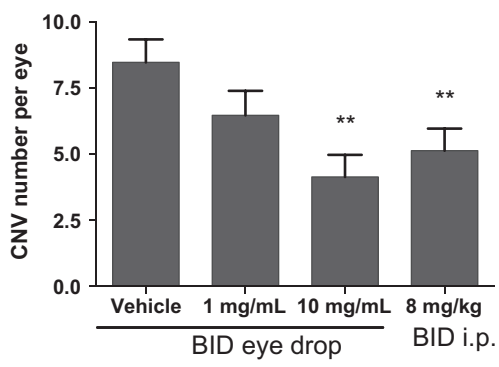

D

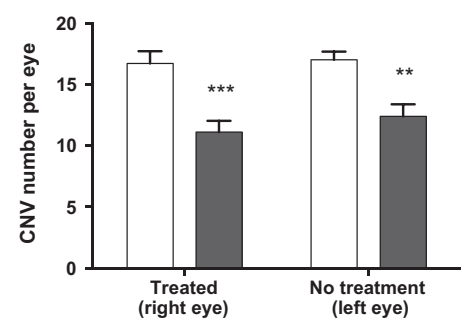

GW766994X 10 mg/mL
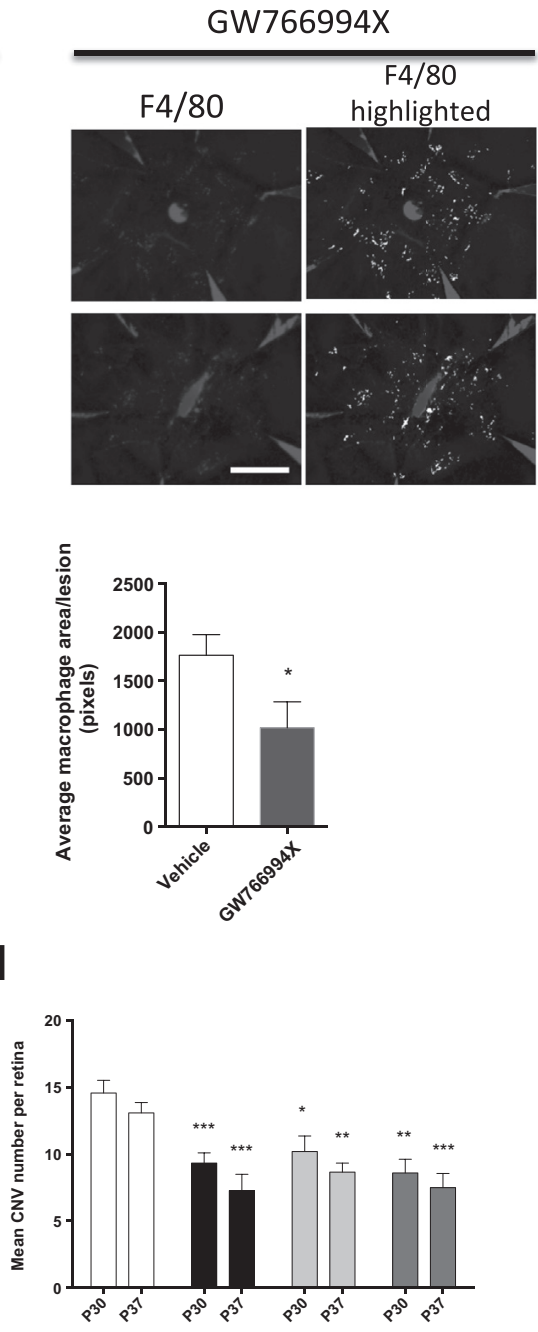

Figure 6 Topical GW766994X dosedependently inhibits choroidal neovascularization (CNV) development in JR5558 mice, with systemic suppression of CNV in the untreated, contralateral eye. A and B: A dose-dependent inhibition of both CNV area and number of lesions per eye, as evaluated by fluorescein angiography (FFA), is observed after topical treatment of JR5588 mice with GW766994X. Twice-daily (BID) eye drop dosing at $10 \mathrm{mg} / \mathrm{mL}$ is as effective as twice-daily systemic i.p. treatment at $8 \mathrm{mg} / \mathrm{kg}$. C and D: Twice-daily eye-drop dosing of GW766994X in only one eye (right eye) results in significant and comparable reduction in both CNV area and lesion number per eye in both the treated and the untreated eye (left eye), suggesting a significant systemic effect of eye-drop dosing of GW766994X. E: Immunohistochemical analysis of eye cups (central region, optic nerve at center) from mice treated twice daily with GW766994X eye drops shows a reduction in the number of macrophages [F4/80, anti-rat Alexa Fluor 594, and highlighted in white using ImageJ software version $1.46 \mathrm{r}$ (NIH, Bethesda, MD; http://imagej.nih.gov/ij)] associated with CNV in both the GW76699Xtreated eye and the untreated contralateral eye, compared with vehicle control. F: A significant reduction in CNV-associated macrophages per field per eye, and per CNV per eye, as determined by image analysis, is observed with topical GW766994X treatment. G and H: Intravitreally injected antibodies against CCR3, showing systemic effect, significantly inhibiting CNV area and lesion number per eye in both the injected eye and the noninjected contralateral eye, especially at postnatal day 37 (after two intravitreal injections). Data are expressed as means \pm SEM. $n=22$ to 26 eyes per group (A and $\mathbf{B}$ ); $n=10$ eyes per group (C and $\mathbf{D}) ; n=6$ eyes per group (F); $n=5$ or 6 eyes per unilaterally injected group and 11 or 12 eyes per bilaterally injected group (G and $\mathbf{H})$. ${ }^{*} P<0.05,{ }^{*} P<0.01$, and $* * * P<0.001$ versus control (unpaired $t$-test with correction for multiple comparisons using the Holm-Šídák method). Scale bars $=1 \mathrm{~mm}(\mathbf{E})$. 


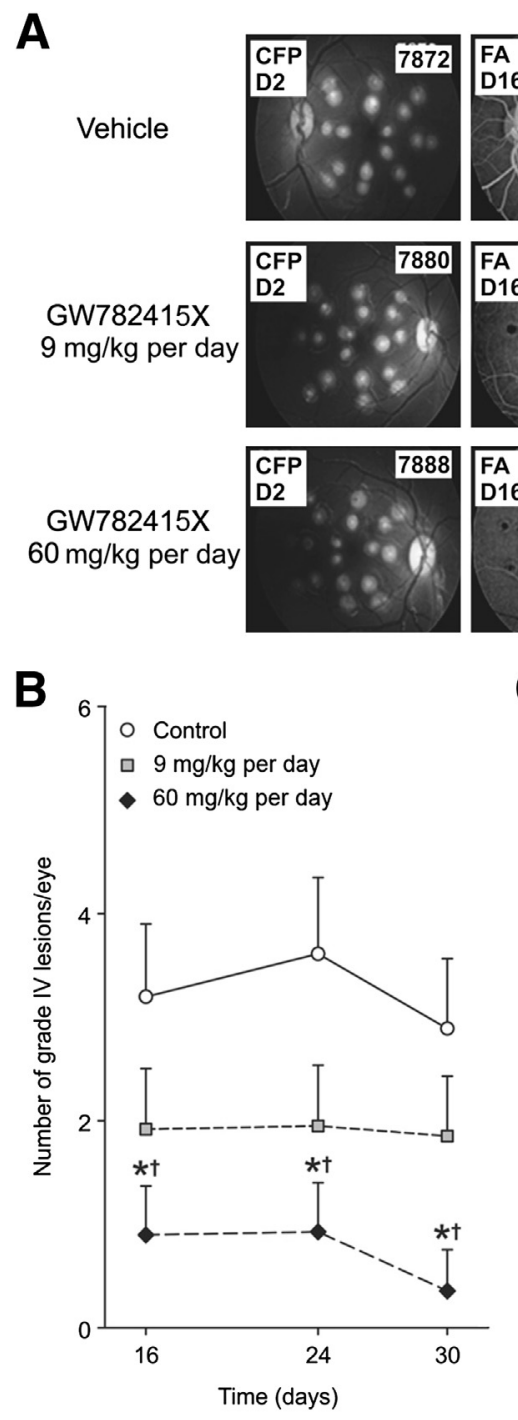

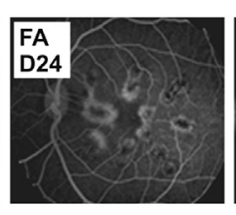
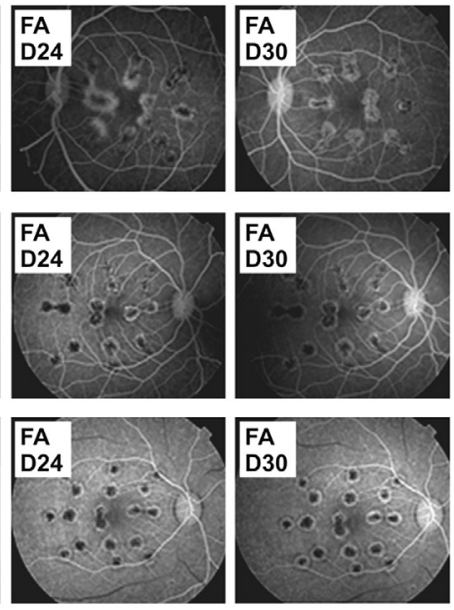

C 9000

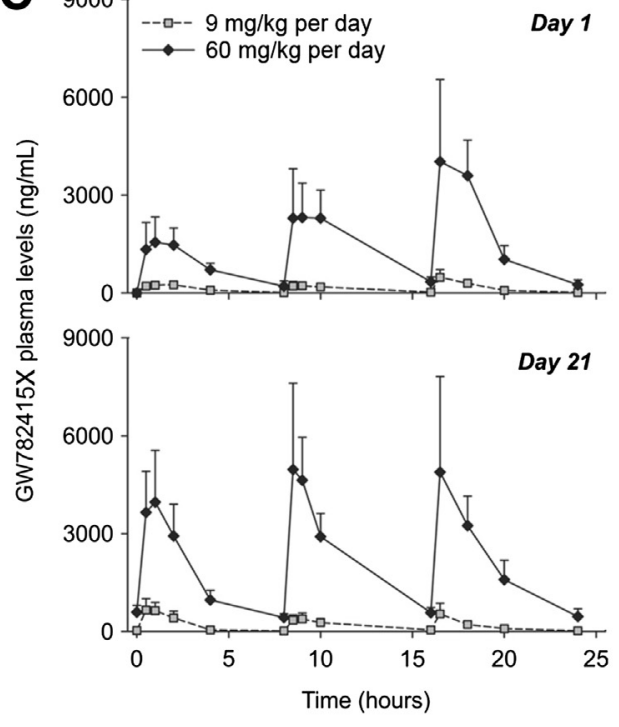

Figure 7 Systemic dosing with GW782415X significantly reduces the number of grade IV choroidal neovascularization (CNV) lesions in a primate model of laser-induced CNV. A: Representative fundoscopy [color fundus photography (CFP), day 2] and fluorescein angiography (FA) (days 16, 24, and 30) of primate eyes after laserphotocoagulation. Animals were treated orally with vehicle, GW782415X at $3 \mathrm{mg} / \mathrm{kg}$ three times per day $(9 \mathrm{mg} / \mathrm{kg}$ per day), or GW782415X at 20 $\mathrm{mg} / \mathrm{kg}$ three times per day (60 mg/ $\mathrm{kg}$ per day), with treatment starting 1 day before photocoagulation and continuing for 29 days. B: Analysis of grade IV lesions in both the left and right eyes of individual cynomolgus monkeys treated as described in $\mathbf{A}$ shows a dose-dependent reduction in lesion number. C: Plasma exposure to GW782415 on days 1 and 21 after oral administration three times daily. Data are expressed as means \pm SD. ${ }^{*} P<0.05$ versus corresponding controls (with Holm's correction for suppression of grade IV CNV lesion); ${ }^{\dagger} P<0.05$ versus vehicle-treated controls (with Holm's correction for a significant doseresponse for GW782415X in this model). $n=12$ eyes per group (B); $n=6$ animals per group (C). formulation (Figure 6, A and B). This level of inhibition of $\mathrm{CNV}$ formation was comparable to that with twice-daily i.p. dosing at $8 \mathrm{mg} / \mathrm{kg}$ (Figures 2 and 6, A and B).

Although eye drops are a topical treatment, systemic exposure via this route has been noted in animal models, particularly in small animals. ${ }^{24-26}$ Potential systemic effects of the topical GW766994X eye drops and the intravitreally injected anti-CCR3 neutralizing antibody were evaluated by limiting these local treatments to one eye and measuring the effects on CNV development in both the dosed eye and the contralateral, nondosed eye. As expected, twice-daily eye-drop dosing of GW766994X at 10 $\mathrm{mg} / \mathrm{mL}$ significantly reduced spontaneous $\mathrm{CNV}$ area and lesion number in the dosed eyes in antagonist-treated animals compared with those in the vehicle-dosed eyes in control animals (53\% of vehicle control for CNV area, $66 \%$ for lesion number; $P<0.001$ for both) (Figure 6, C and D). Interestingly, similar reductions in spontaneous $\mathrm{CNV}$ area and lesion number per eye were also observed in the contralateral, nondosed eyes (to $53 \%$ for $\mathrm{CNV}$ area and
$73 \%$ for lesion number for the nondosed eye versus nondosed vehicle controls; $P<0.001$ and $P<0.01$, respectively); indeed, the effects in the contralateral, nondosed eye were not significantly different from those in the dosed eye (Figure 6, C and D). The extent of inhibition of CNV, and especially the number of lesions per eye, with a single dosed eye (Figure 6, C and D) was less than that observed when both eyes were treated with the eye drops (Figure 6, $A$ and B).

Topical GW766994X also significantly inhibited macrophage recruitment to the $\mathrm{CNV}$ in both the treated and the contralateral, untreated eye compared with vehicle control (Figure 6, E and F). Similarly, two intravitreal injections of anti-CCR3 antibody into a single eye significantly suppressed CNV area and number of lesions in both eyes with similar efficacy at P37. The effects at P30, after one intravitreal injection in a single eye, were slightly less robust, but the CNV area and lesion number were still suppressed in the contralateral, untreated eye (Figure 6, G and $\mathrm{H}$ ). 
Table 1 Ocular Pharmacokinetic Data from Cynomolgus Monkeys Treated Systemically with Oral Dosing of GW782415X

\begin{tabular}{llcc}
\hline & \multicolumn{2}{l}{ Regimen } \\
\cline { 2 - 4 } Ocular region & Placebo & GW782415X & GW782415X \\
Cornea & BLQ & 9 mg/kg per day & $228 \pm 94.7 \mathrm{ng} / \mathrm{g}$ \\
Aqueous humor & BLQ & BLQ & $127 \pm 36.9 \mathrm{ng} / \mathrm{mL}$ \\
Iris/ciliary body & BLQ & $8460 \pm 2510 \mathrm{ng} / \mathrm{g}$ & $60,800 \pm 14,500 \mathrm{ng} / \mathrm{g}$ \\
Retina (punch) & BLQ & $253 \pm 343 \mathrm{ng} / \mathrm{g}$ & $1370 \pm 495 \mathrm{ng} / \mathrm{g}$ \\
Retina (remaining) & BLQ & $735 \pm 453 \mathrm{ng} / \mathrm{g}$ & $4670 \pm 1690 \mathrm{ng} / \mathrm{g}$ \\
Choroid (punch) & BLQ & $51,300 \pm 21,100 \mathrm{ng} / \mathrm{g}$ & $186,000 \pm 53,100 \mathrm{ng} / \mathrm{g}$ \\
Choroid (remaining) & BLQ & $47,800 \pm 19,900 \mathrm{ng} / \mathrm{g}$ & $281,000 \pm 114,000 \mathrm{ng} / \mathrm{g}$ \\
Vitreous humor & BLQ & $5.93 \pm 6.88 \mathrm{ng} / \mathrm{mL}$ & $92.1 \pm 10.8 \mathrm{ng} / \mathrm{mL}$ \\
\hline
\end{tabular}

Ocular tissue levels were isolated 29 days after thrice-daily oral administration of the CCR3 antagonist. Data are expressed as means \pm SD. $n=4$ eyes per dose regimen.

BLQ, below limit of quantitation (10 $\mathrm{ng} / \mathrm{g}$ tissue).

\section{Oral Dosing of the CCR3 Antagonist GW782415X Limits Laser-Induced Choroidal CNV in the Cynomolgus Monkey}

To better determine the translational potential of CCR3 antagonists for treating wet AMD in patients, systemic dosing of GW782415X, ${ }^{27}$ a small-molecule CCR3 antagonist similar to GW766994X, was tested in a laser-induced CNV model in nonhuman primates. GW782415X was selected for the following reasons: i) it is derived from the same parental compound as is GW766994X (Supplemental Figure S1); ii) GW782415X had good potency against cynomolgus CCR3 and showed reasonable systemic exposure in primates after oral administration, with low interanimal variability (Supplemental Table S1), whereas the characterization of GW766994X bioavailability after oral dosing in cynomolgus monkeys was lacking; iii) the 2 compounds have a similar affinity for human CCR3 (equilibrium dissociation constant for CCR3, 7.84 with GW782415X and 7.63 with GW766994X); and iv) a single oral dose of $20 \mathrm{mg} / \mathrm{kg}$ GW782415X in cynomolgus monkeys suppressed CCL11-mediated shape change in whole blood (unpublished data).

Starting 1 day before photocoagulation and continuing for 28 consecutive days after $\mathrm{CNV}$ induction, cynomolgus monkeys were treated with vehicle, $3 \mathrm{mg} / \mathrm{kg}$ GW782415X, or $20 \mathrm{mg} / \mathrm{kg} \mathrm{GW} 782415 \mathrm{X}$ by oral gavage three times per day (every 8 hours). FFA showed a clear decrease in lesion size (hyperfluorescence) in the treated monkeys (Figure 7A). Indeed, oral dosing of GW782415X at $20 \mathrm{mg} / \mathrm{kg}$ resulted in a statistically significant, dose-dependent reduction in the number of grade IV CNV lesions at 16, 24, and 30 days after the initiation of treatment compared with that in controls ( $P<0.05$ for each day, Holm's correction) (Figure 7B). Although the reduction in the number of grade IV lesions with $3 \mathrm{mg} / \mathrm{kg}$ GW782415X was not statistically different from that in controls (given the low power of the study), the dose relationship achieved statistical significance independent of logarithm dose-scaling or linear dose-scaling assumptions ( $P<0.05$, Holm's correction) (Figure 7B).
Assessment of Systemic and Tissue Levels of CCR3 Antagonist in Cynomolgus Monkeys Orally Dosed with GW782415X

Systemic exposure to GW782415 administered at $9 \mathrm{mg} / \mathrm{kg}$ per day ( $3 \mathrm{mg} / \mathrm{kg}$ per dose, three times daily) and $60 \mathrm{mg} / \mathrm{kg}$ per day $(20 \mathrm{mg} / \mathrm{kg}$ per dose, three times daily) of GW782415X (hydrochloride salt) was measured several times over the course of the study (Figure 7C). On day 1 of GW782415X dosing, the maximum plasma concentration was observed at 16.5 hours after the first dose $(0.5$ hours after the third dose). On day 21 of dosing, similar maximum plasma concentrations were observed after each oral dose, suggesting that the minimum plasma concentrations had reached steady state. Systemic exposure, as measured by mean area under the plasma concentration-time curve up to the last measurable concentration and maximum plasma concentrations, increased in a slightly greater than doseproportional manner. For a 6.7 -fold increase in dose from 9 to $60 \mathrm{mg} / \mathrm{kg}$ per day, mean area under the plasma concentration-time curve up to the last measurable concentration and maximum plasma concentration increased 9.8- and 8.6-fold, respectively, on day 1 and 11.2- and 8.9-fold, respectively, on day 21 . After 21 days of dosing three times daily, there was no difference (more than twofold) in systemic exposure between days 1 and 21 . On day 28 , the mean trough concentrations of GW782415 in the plasma were $33.3 \pm 2.7$ $\mathrm{ng} / \mathrm{mL}$ and $685 \pm 312 \mathrm{ng} / \mathrm{mL}$ (means $\pm \mathrm{SD}$ ) with dosing of 9 and $60 \mathrm{mg} / \mathrm{kg}$ per day, respectively.

Levels of GW782415 in ocular tissues were determined at the conclusion of the systemic dosing study. The levels of GW782415 in the RPE/choroid after oral administration were significantly higher than were those in the retina; RPE/ choroid levels were 186,000 $\pm 53,100 \mathrm{ng} / \mathrm{g}$ (central region) and 281,000 $\pm 114,000 \mathrm{ng} / \mathrm{g}$ (remaining RPE/choroid), and retinal levels were $1370 \pm 495 \mathrm{ng} / \mathrm{g}$ (central region) and $4670 \pm 1690 \mathrm{ng} / \mathrm{g}$ (remaining retina) at the dose of $60 \mathrm{mg} / \mathrm{kg}$ per day (Table 1). Levels of GW782415 in the RPE/choroid and retina were three to five times greater in the higher-dose 
Table 2 Concentrations of GW766994 in Tissues (Punch Samples) and Plasma of Cynomolgus Monkeys Treated with Intravitreal Suspension Injection, Intravitreal Implantation, or Topical Eye Drop Administration of GW766994X

\begin{tabular}{|c|c|c|c|c|c|c|c|c|}
\hline \multirow{2}{*}{$\begin{array}{l}\text { GW766994X } \\
\text { treatment } \\
\text { condition }\end{array}$} & \multicolumn{4}{|c|}{ Tissue concentrations of GW766994 on day $29, \mathrm{ng} / \mathrm{mL}$} & \multicolumn{4}{|c|}{ Plasma concentrations of GW766994, $\mathrm{ng} / \mathrm{mL}$} \\
\hline & $\begin{array}{l}\text { Retina, } \\
\text { dosed eye }\end{array}$ & $\begin{array}{l}\text { Retina, } \\
\text { nondosed eye }\end{array}$ & $\begin{array}{l}\text { Choroid, } \\
\text { dosed eye }\end{array}$ & $\begin{array}{l}\text { Choroid, } \\
\text { nondosed eye }\end{array}$ & Day 8 & Day 15 & Day 22 & Day 29 \\
\hline $\begin{array}{l}\text { Single-eye } \\
\text { injection, } \\
10 \% \mathrm{w} / \mathrm{v}\end{array}$ & $46,600 \pm 29,000$ & $69.5 \pm 29.5$ & $91,500 \pm 42,900$ & $3490 \pm 92.1$ & & $6.92 \pm 1.27$ & $4.72 \pm 1.54$ & $6.99 \pm 2.82$ \\
\hline $\begin{array}{l}\text { Bilateral implant, } \\
0.3 \mathrm{mg}\end{array}$ & $440 \pm 188$ & & $1170 \pm 524$ & & $0.349 \pm 0.033$ & $0.201 \pm 0.028$ & $0.164 \pm 0.020$ & $0.158 \pm 0.020$ \\
\hline $\begin{array}{l}\text { Bilateral topical, } \\
10 \mathrm{mg} / \mathrm{mL}\end{array}$ & $295 \pm 442$ & & $3490 \pm 921$ & & $3.81 \pm 0.886$ & $2.48 \pm 0.882$ & $2.45 \pm 0.728$ & $1.71 \pm 0.925$ \\
\hline
\end{tabular}

Intravitreal injections were administered at $5 \mathrm{mg} /$ eye per dose on days 8 and 22. The implant preloaded with approximately $0.1 \mathrm{mg}$ and $0.3 \mathrm{mg}$ of GW766994 were intended to release approximately 0.002 and $0.010 \mathrm{mg}$ per day, respectively. Both devices were implanted on day 1 . Animals dosed topically were given eye drops twice daily $(0.5 \mathrm{mg}$ /eye per dose), with doses approximately 8 hours apart, on days 1 to $29 . n=6$ eyes analyzed for each bilateral treatment, $n=3$ eyes analyzed for the single-eye treatment.

group compared with those in the lower-dose group and were generally low in ocular tissues of the anterior segment, with the exception of the iris/ciliary body, where levels were approximately sevenfold greater in the higher-dose group compared with those in the lower-dose group (Table 1).

Intravitreal, Sustained-Release Intravitreal, and Topical GW766994X in Cynomolgus Monkeys Fails To Suppress CNV Induced by Photocoagulation

In light of the significant systemic effects of locally delivered CCR3 antagonists in inhibiting the CNV in the JR5558 mouse model, the effect of locally administered GW766994X was evaluated in cynomolgus monkeys. Local delivery of GW766994X was achieved by intravitreal suspension injection, indwelling sustained delivery, and eye drops (Table 2). GW766994X was used for these local delivery experiments because it is effective against primate CCR $3,{ }^{28}$ is available in both slow-release suspension and eye-drop formulations, and is compatible with the indwelling device for sustained delivery. Animals were intravitreally injected (in both eyes or in a single eye) with $50 \mu \mathrm{L}$ of a $100 \mathrm{mg} / \mathrm{mL}$ GW766994X suspension on days 8 and 22 after the induction of CNV. On day 1, other animals received indwelling devices preloaded with approximately $0.1 \mathrm{mg}$ of GW766994X (intended to release approximately $0.002 \mathrm{mg}$ per day) or $0.3 \mathrm{mg}$ of GW766994X (intended to release approximately $0.010 \mathrm{mg}$ per day) (Supplemental Table S2). A separate group of animals was topically dosed twice daily with GW766994X $(50-\mu \mathrm{L}$ eye drop of a $10 \mathrm{mg} / \mathrm{mL}$ solution) applied to each eye approximately 8 hours apart, from days 1 to 29 .

In contrast to the efficacy observed with oral dosing of GW782415X for laser-induced CNV (Figure 4, A and B) and local dosing of GW766994X in JR5558 mice (Figure 7), bilateral intravitreal injection of $5 \mathrm{mg}$ of GW766994X as a $100 \mathrm{mg} / \mathrm{mL}$ suspension was ineffective in suppressing the emergence of grade IV CNV lesions (unpublished data). Similarly, unilateral injection of a 5-mg GW766994X suspension failed to demonstrate a therapeutic effect in both the injected and the noninjected contralateral eyes. Intraocular sustained-release devices delivering GW766994X and topical application of the CCR3 antagonist also had no impact on the emergence of grade IV CNV lesions compared with controls (unpublished data).

\section{Ocular Administration of GW766994X in Cynomolgus Monkeys Results in Good Local Drug Delivery but Low Systemic Drug Exposure}

The lack of pharmacological effect observed with intravitreal, sustained-release intravitreal, and topical administration of GW76694X in cynomolgus monkeys cannot be explained by low ocular drug delivery. High levels of GW766994 were detected in the RPE/choroid $(109,000 \pm 37,900 \mathrm{ng} / \mathrm{g})$ and in the retina $(43,200 \pm 12,100 \mathrm{ng} / \mathrm{g})$ in the bilateral intravitreal suspension injection group (Table 2). Interestingly, levels of GW766994 in the RPE/choroid were lower with local delivery (Table 2) than with oral dosing $(186,000 \pm 53,100 \mathrm{ng} / \mathrm{g}$ ) (Table 1), but retinal levels were significantly higher, which is consistent with intravitreal delivery. ${ }^{29}$ Similar exposure was noted in animals dosed in a single eye, with dosed-eye RPE/choroidal and retinal levels of 91,500 $\pm 42,900 \mathrm{ng} / \mathrm{g}$ and 46,600 $\pm 29,000 \mathrm{ng} / \mathrm{g}$, respectively (Table 2). GW766994 was also detected in the $\mathrm{RPE} /$ choroid and retina from the contralateral, nondosed eye, albeit at dramatically lower levels, with $3490 \pm 921$ 
$\mathrm{ng} / \mathrm{g}$ and $69.5 \pm 29.5 \mathrm{ng} / \mathrm{g}$ observed in the RPE/choroid and retina, respectively.

Systemic exposure via ocular delivery is also supported by the increase in plasma levels of antagonist noted after intravitreal administration of GW766994X (Table 2). The highest systemic exposure was measured after bilateral intravitreal suspension injection, with plasma levels of $19.4 \pm 7.0 \mathrm{ng} / \mathrm{mL}$, $11.1 \pm 7.2 \mathrm{ng} / \mathrm{mL}$, and $20.6 \pm 13.5 \mathrm{ng} / \mathrm{mL}$ on days 15,22 , and 29 , respectively. Systemic exposure after intravitreal suspension injection into a single eye yielded plasma values approximately two- to threefold less than with bilateral suspension administration. The implants and topical administration yielded the lowest levels of GW766994 in ocular tissues and in plasma (Table 2). Interesting, the RPE/choroid levels of GW766994 were comparable between the topically dosed eyes (3560 \pm 907 $\mathrm{ng} / \mathrm{g})$ and the noninjected contralateral eyes (3490 \pm 921 $\mathrm{ng} / \mathrm{g}$ ) from the unilateral intravitreal suspension injection group, suggesting that RPE/choroid exposure is via the systemic circulation rather than through the retina in the topically administered group.

\section{Discussion}

Our findings illustrate a direct functional role for CCR3 in the development of neovascular lesions in both injuryinduced and spontaneous CNV and suggest that macrophages may be an important source of CCR3 ligands in $\mathrm{CNV}$. We have shown that small-molecule inhibitors of CCR3 can be used for treating CNV in several models, including a nonhuman primate model, and that systemic delivery of the antagonist may be required for efficacy. Finally, we have shown that treatment with a CCR3 antagonist in combination with anti-VEGFR2 antibody can yield an additive therapeutic effect on CNV area.

Our findings that CCR3 is expressed on new vessels and leukocytes around the CNV lesion in JR5558 mice and that ligands of CCR3 are expressed by $\mathrm{CNV}$-associated macrophages suggest a systemic role for CCR3 in promoting angiogenesis and recruiting circulating leukocytes. Others have also reported CCR3 expression in the vascular endothelial cells of CNV vessels as well as in choroidal endothelial cells and leukocytes, ${ }^{9,14,15,30,31}$ but this is the first report of macrophages as a source of CCR3 ligands in CNV. Our findings support a possible mechanism of CCR3 activity in which the CNV neovessels, leukocytes, and likely the choroidal endothelial cells ${ }^{9}$ express CCR3 and respond to CCR3 ligands that are produced in the subretinal space (eg, by recruited macrophages). This hypothesis is consistent with our finding that intravitreally injected antibodies against CCL11 and CCL24 inhibited both macrophage recruitment and CNV development.

Intravitreally injected anti-CCR3 antibodies, antibodies against CCR3 ligands, and pharmacological inhibitors of
CCR3 have all been shown to be effective in limiting the extent of $\mathrm{CNV}$ after laser induction in mice, ${ }^{14,15}$ but we are the first to demonstrate this effect in spontaneously developed $\mathrm{CNV}$, a model that more closely mimics disease progression in humans, as well as in primates. In both the murine models and the nonhuman primate model of CNV, systemic delivery of the CCR3 antagonist was necessary for the effective inhibition of CNV. Ocular dosing of CCR3 antagonists significantly limited CNV development in the JR5558 mouse model not only in the dosed eyes but also in the contralateral, nondosed eyes - with efficacy comparable to that of systemic oral dosing, suggesting that the therapeutic effects observed with ocular delivery of CCR3 antagonists in the mouse were mainly due to systemic exposure. Others have observed significant systemic exposure after local drug delivery to the eye in experimental animals and in humans, and such systemic effects were more prominent in neonates, likely due to smaller body size. ${ }^{24-26}$ These observations have important implications for the development of CCR3 antagonists for ophthalmic applications.

Variation in systemic delivery may account for the conflicting efficacy reported for CCR3 antagonism in rodent models of CNV, as well as for the differences in efficacy after the topical delivery of CCR3 antagonists in mice compared with monkeys. Both systemic and intravitreal administration of CCR3 antagonists has been shown to suppress CNV in mouse photocoagulation models ${ }^{14,15}$ and, as we have shown, both of these routes provide systemic delivery of the antagonists. In contrast, subretinal injection of Matrigel loaded with antagonists likely achieves high ocular levels of CCR3 inhibition but low systemic exposure-a possible explanation for the lack of effect when CCR3 antagonist was subretinally delivered in Matrigel. ${ }^{18}$ In the cynomolgus monkeys, ocular delivery resulted in substantially (approximately 250-fold) lower systemic exposure than oral administration at high doses while achieving similar levels of CCR3 antagonist in the eye. Therefore, the lack of CNV inhibitory activity after local administration is not likely the result of low ocular exposure but might instead be due to lower systemic exposure to the CCR3 antagonist. Consistent with this hypothesis, the oral doses that most effectively suppressed grade IV lesions in the monkeys resulted in $>95 \%$ CCR3 occupancy by the antagonist at trough.

Given the variable response of patients to anti-VEGF therapies, ${ }^{3-5}$ it is interesting to note that some of the CCR3 effects on CNV appear to be independent of VEGFR2 activity, a finding consistent with the previous assertion that CCR3-mediated suppression of laser-induced CNV was at least partly independent of the VEGF pathway. ${ }^{14}$ The effects of systemic GW766994X on CNV permeability are likely mediated by a pathway that partially overlaps with the VEGF pathway in the JR5558 model of spontaneous CNV. Thus, combination therapy with anti-VEGF and CCR3 antagonists, which likely target both the new vessels and the inflammatory pathway, could yield a better therapeutic effect. 


\section{Acknowledgments}

We thank Clara Andonian and Caroline Sychterz of GlaxoSmithKline for the quantitation of GW766994 and GW782415 in plasma and ocular tissues, Shannon Bunker of University College London for animal dosing and FFA experiments, and Drs. Patricia D'Amore and Anne Goodwin for critical reading of the manuscript and manuscript editing, respectively.

\section{Supplemental Data}

Supplemental material for this article can be found at http://dx.doi.org/10.1016/j.ajpath.2015.04.029.

\section{References}

1. Ambati J, Ambati BK, Yoo SH, Ianchulev S, Adamis AP: Age-related macular degeneration: etiology, pathogenesis, and therapeutic strategies. Surv Ophthalmol 2003, 48:257-293

2. Kovach JL, Schwartz SG, Flynn HW Jr, Scott IU: Anti-VEGF treatment strategies for wet AMD. J Ophthalmol [Internet], 2012, doi: $10.1155 / 2012 / 786870$

3. Rofagha S, Bhisitkul RB, Boyer DS, Sadda SR, Zhang K: Seven-year outcomes in ranibizumab-treated patients in ANCHOR, MARINA, and HORIZON: a multicenter cohort study (SEVEN-UP). Ophthalmology 2013, 120:2292-2299

4. Scott AW, Bressler SB: Long-term follow-up of vascular endothelial growth factor inhibitor therapy for neovascular age-related macular degeneration. Curr Opin Ophthalmol 2013, 24:190-196

5. Takeda AL, Colquitt J, Clegg AJ, Jones J: Pegaptanib and ranibizumab for neovascular age-related macular degeneration: a systematic review. Br J Ophthalmol 2007, 91:1177-1182

6. Foxton RH, Finkelstein A, Vijay S, Dahlmann-Noor A, Khaw PT, Morgan JE, Shima DT, Ng YS: VEGF-A is necessary and sufficient for retinal neuroprotection in models of experimental glaucoma. Am J Pathol 2013, 182:1379-1390

7. Saint-Geniez M, Maharaj AS, Walshe TE, Tucker BA, Sekiyama E, Kurihara T, Darland DC, Young MJ, D'Amore PA: Endogenous VEGF is required for visual function: evidence for a survival role on Müller cells and photoreceptors. PLoS One 2008, 3:e3554

8. Nishijima K, Ng YS, Zhong L, Bradley J, Schubert W, Jo N, Akita J, Samuelsson SJ, Robinson GS, Adamis AP, Shima DT: Vascular endothelial growth factor-A is a survival factor for retinal neurons and a critical neuroprotectant during the adaptive response to ischemic injury. Am J Pathol 2007, 171:53-67

9. Wang H, Wittchen ES, Jiang Y, Ambati B, Grossniklaus HE, Hartnett ME: Upregulation of CCR3 by age-related stresses promotes choroidal endothelial cell migration via VEGF-dependent and -independent signaling. Invest Ophthalmol Vis Sci 2011, 52: $8271-8277$

10. Sharma NK, Gupta A, Prabhakar S, Singh R, Bhatt AK, Anand A: CC chemokine receptor-3 as new target for age-related macular degeneration. Gene 2013, 523:106-111

11. Mo FM, Proia AD, Johnson WH, Cyr D, Lashkari K: Interferon gamma-inducible protein-10 (IP-10) and eotaxin as biomarkers in agerelated macular degeneration. Invest Ophthalmol Vis Sci 2010, 51: 4226-4236

12. Falk MK, Singh A, Faber C, Nissen MH, Hviid T, Sorensen TL: Blood expression levels of chemokine receptor CCR3 and chemokine CCL11 in age-related macular degeneration: a case-control study. BMC Ophthalmol [Internet] 2014, 14; doi:10.1186/1471-2415-14-22
13. Sharma NK, Prabhakar S, Gupta A, Singh R, Gupta PK, Gupta PK, Anand A: New biomarker for neovascular age-related macular degeneration: eotaxin-2. DNA Cell Biol 2012, 31:1618-1627

14. Takeda A, Baffi JZ, Kleinman ME, Cho WG, Nozaki M, Yamada K, Kaneko H, Albuquerque RJ, Dridi S, Saito K, Raisler BJ, Budd SJ, Geisen P, Munitz A, Ambati BK, Green MG, Ishibashi T, Wright JD, Humbles AA, Gerard CJ, Ogura Y, Pan Y, Smith JR, Grisanti S, Hartnett ME, Rothenberg ME, Ambati J: CCR3 is a target for age-related macular degeneration diagnosis and therapy. Nature 2009, 460:225-230

15. Mizutani T, Ashikari M, Tokoro M, Nozaki M, Ogura Y: Suppression of laser-induced choroidal neovascularization by a CCR3 antagonist. Invest Ophthalmol Vis Sci 2013, 54:1564-1572

16. Nagai N, Lundh von Leithner P, Izumi-Nagai K, Hosking B, Chang B, Hurd R, Adamson P, Adamis AP, Foxton RH, Ng YS, Shima DT: Spontaneous CNV in a novel mutant mouse is associated with early VEGF-A-driven angiogenesis and late-stage focal edema, neural cell loss, and dysfunction. Invest Ophthalmol Vis Sci 2014, 55:3709-3719

17. Nork TM, Dubielzig RR, Christian BJ, Miller PE, Miller JM, Cao J, Zimmer EP, Wiegand SJ: Prevention of experimental choroidal neovascularization and resolution of active lesions by VEGF trap in nonhuman primates. Arch Ophthalmol 2011, 129:1042-1052

18. Li Y, Huang D, Xia X, Wang Z, Luo L, Wen R: CCR3 and choroidal neovascularization. PLoS One 2011, 6:e17106

19. Giani A, Thanos A, Roh MI, Connolly E, Trichonas G, Kim I, Gragoudas E, Vavvas D, Miller JW: In vivo evaluation of laserinduced choroidal neovascularization using spectral-domain optical coherence tomography. Invest Ophthalmol Vis Sci 2011, 52: 3880-3887

20. Robbie SJ, Lundh von Leithner P, Ju M, Lange CA, King AG, Adamson P, Lee D, Sychterz C, Coffey P, Ng YS, Bainbridge JW, Shima DT: Assessing a novel depot delivery strategy for noninvasive administration of VEGF/PDGF RTK inhibitors for ocular neovascular disease. Invest Ophthalmol Vis Sci 2013, 54:1490-1500

21. Ferrara N, Gerber HP, LeCouter J: The biology of VEGF and its receptors. Nat Med 2003, 9:669-676

22. Kimoto K, Kubota T: Anti-VEGF Agents for Ocular Angiogenesis and Vascular Permeability. J Ophthalmol 2012, 2012:852183

23. Jamaluddin MS, Wang X, Wang H, Rafael C, Yao Q, Chen C: Eotaxin increases monolayer permeability of human coronary artery endothelial cells. Arterioscler Thromb Vasc Biol 2009, 29:2146-2152

24. Salminen L: Review: systemic absorption of topically applied ocular drugs in humans. J Ocul Pharmacol 1990, 6:243-249

25. Urtti A, Salminen L: Minimizing systemic absorption of topically administered ophthalmic drugs. Surv Ophthalmol 1993, 37:435-456

26. Rozette NA, Matragoon S, Sethi S, Goei S, Manasco KB, ElRemessy AB: Systemic effects of ophthalmic cyclopentolate on body weight in neonatal mice. Neonatology 2014, 106:37-41

27. Nakamura T, Ohbayashi M, Toda M, Hall DA, Horgan CM, Ono SJ: A specific CCR3 chemokine receptor antagonist inhibits both early and late phase allergic inflammation in the conjunctiva. Immunol Res 2005, 33:213-221

28. Neighbour H, Boulet LP, Lemiere C, Sehmi R, Leigh R, Sousa AR, Martin J, Dallow N, Gilbert J, Allen A, Hall D, Nair P: Safety and efficacy of an oral CCR3 antagonist in patients with asthma and eosinophilic bronchitis: a randomized, placebo-controlled clinical trial. Clin Exp Allergy 2014, 44:508-516

29. Geroski DH, Edelhauser HF: Drug delivery for posterior segment eye disease. Invest Ophthalmol Vis Sci 2000, 41:961-964

30. Ponath PD, Qin S, Post TW, Wang J, Wu L, Gerard NP, Newman W, Gerard C, Mackay CR: Molecular cloning and characterization of a human eotaxin receptor expressed selectively on eosinophils. J Exp Med 1996, 183:2437-2448

31. He J, Chen Y, Farzan M, Choe H, Ohagen A, Gartner S, Busciglio J, Yang X, Hofmann W, Newman W, Mackay CR, Sodroski J, Gabuzda D: CCR3 and CCR5 are co-receptors for HIV-1 infection of microglia. Nature 1997, 385:645-649 